(C) Dereito Vol.28, n01:209-243 (Xaneiro-Xuño, 2019) • ISSN 1132-9947

\title{
EL ACUERDO DE PESCA ENTRE LA UNIÓN EUROPEA Y EL REINO DE MARRUECOS Y SU PROTOCOLO DE APLICACIÓN 2018-2022 A LA LUZ DE LA ÚLTIMA JURISPRUDENCIA DEL TJUE Y DEL DERECHO INTERNACIONAL
}

The fishing agreement between the European Union and the Kingdom of Morocco and its application protocol 2018-2022 at the end of the last jurisprudence of JTEU and international law

DOI: http://dx.doi.org/10.15304/dereito.28.1.5807

MARÍA IgLesias BerLANGA ${ }^{1}$

Profesora Ayudante Doctora

Universidad Complutense de Madrid

Migles06@ucm.es

\section{Resumen}

Este trabajo examina, desde una perspectiva crítica, la celebración del Acuerdo de colaboración de pesca sostenible entre la Unión Europea (UE) y el Reino de Marruecos y su Protocolo de aplicación 2018-2022 a la luz, fundamentalmente, de: 1) la sentencia del Tribunal de Justicia de la Unión Europea (TJUE), de 27 de febrero de 2018, en el caso C-266/16, cuyo origen se remonta a una petición de cuestión prejudicial por parte del Tribunal Superior de Justicia (Inglaterra y País de Gales) de 2016, con respecto a la validez del Acuerdo de Colaboración de 2007 y de su Protocolo de aplicación 2014-2018, y de sus correspondientes actos de Derecho derivado; y 2) del Derecho internacional, en particular, a tenor de la aplicación territorial de los tratados y del principio de soberanía permanente sobre los recursos naturales.

Palabras clave: Cuestión prejudicial; Sáhara Occidental; principio de libre determinación; aplicación territorial de los tratados; principio de soberanía permanente sobre los recursos naturales.

\section{Abstract}

This paper examines, from a critical perspective, the conclusion of the Sustainable Fisheries Partnership Agreement between the European Union and the Kingdom of Morocco and its implementing Protocol 2018-2022 in the light, essentially, of two considerations: 1) the judgement of the Court of Justice of the European Union (27 February 2018), in Case C-266/16, the origin of which dates back to a request for a preliminary ruling by the High Court of Justice (England and Wales) of 2016 with regard to the validity of 2007 Partneship Agreement and its Implementing Protocol 2014-2018 and its corresponding acts of secondary law; and 2)

\footnotetext{
${ }^{1}$ https://orcid.org/0000-0001-7373-4927

2 Dicha decisión fue solicitada mediante una resolución de 27 de abril de 2016, que fue recibida en el Tribunal de Justicia el 13 de mayo de 2016.
}

Recibido: 28/09/2018. Aceptado: 15/11/2018. 
International Law, namely, the territorial application of the treaties and the principle of permanent sovereignty over natural resources.

Keywords: Preliminary ruling; Western Sahara; principle of selfdetermination; the territorial application of the treaties; principle of permanent sovereignty over natural resources.

\section{SUMARIO}

I.- INTRODUCCIÓN. II.- LA ACTUALIDAD DEL ESTATUTO JURÍDICO DEL SÁHARA OCCIDENTAL. UNA BREVE REFERENCIA. III.- EL ACUERDO DE PESCA Y SU PROTOCOLO DE APLICACIÓN 2018-2022. 3.1. La sentencia del TJUE, de 27 de febrero de 2018, en el caso C-266/16. 3.2.- El alcance espacial del Acuerdo de Pesca y de su Protocolo de aplicación 2018-2022 según el Derecho de los Tratados. 3.3.- El "respeto" del derecho del pueblo colonial a sus recursos naturales (pesqueros). 3.4.- Los intereses recíprocos de la UE y del Reino de Marruecos en la celebración del Acuerdo de Pesca y de su Protocolo de aplicación 2018-2022. IV.OBSERVACIONES FINALES. V.- BIBLIOGRAFÍA

\section{INTRODUCCIÓN}

Al cabo de varias rondas de negociaciones, la Unión Europea (en adelante, UE) y el Reino de Marruecos rubricaron, el 24 de julio de 2018, un Acuerdo de colaboración de pesca sostenible (en lo sucesivo, el Acuerdo de Pesca) y un nuevo Protocolo de aplicación 2018-2022. Sin embargo, como trataremos de exponer en las siguientes páginas, la aplicación territorial de estos textos no se ajusta in toto a la última jurisprudencia del Tribunal de Justicia de la Unión Europea (TJUE) en la materia, ni a determinadas cuestiones fundamentales de Derecho internacional reguladas en diferentes instrumentos jurídicos como la Carta de las Naciones Unidas (ONU), el Convenio de Viena de 1969 sobre Derecho de los Tratados, distintas resoluciones de la Asamblea General de la ONU y/o la propia jurisprudencia de la Corte Internacional de Justicia (CIJ).

Habida cuenta de que el origen de la sentencia del TJUE, de 27 de febrero de 2018, en el asunto C-266/16, se remonta a una petición de cuestión prejudicial por parte del Tribunal Superior de Justicia (Inglaterra y País de Gales) de 2016, con respecto a la validez inter alia del Acuerdo de Colaboración de 2007 y de su Protocolo de aplicación 2014-2018, a saber, los predecesores convencionales más cercanos del actual Acuerdo de Pesca y de su Protocolo de aplicación 2018-2022, examinaremos, en primer lugar, dicha cuestión prejudicial y la respuesta del TJUE en orden a la aplicación espacial de los tratados para, seguidamente, abordar el actual estatuto jurídico del Sáhara Occidental y, sobre estas premisas, analizar finalmente si estos últimos textos son conformes o no con el Derecho internacional, especialmente en lo que se refiere a la capacidad convencional de Marruecos para celebrar acuerdos de este tipo y a su concreta extensión territorial.

En el asunto C-266/16, el Tribunal Superior de Justicia (Inglaterra y País de Gales), Sala de lo Contencioso-Administrativo, Reino Unido, (High Court of Justice (England \& Wales), Queen's Bench Division 
(Administrative Court), solicitó al TJUE una decisión prejudicial ${ }^{2}$ con arreglo al artículo 267 del Tratado de Funcionamiento de la Unión Europea $(T F U E)^{3}$. Como es sabido, el procedimiento prejudicial es útil cuando ante un órgano jurisdiccional nacional se plantee una cuestión de interpretación, nueva y de interés general, para la aplicación uniforme del Derecho de la Unión Europea (UE) o cuando la jurisprudencia existente no parezca dar la necesaria orientación para abordar una nueva situación legal ${ }^{4}$. De esta suerte, la petición de decisión prejudicial se presentó en el contexto de dos litigios seguidos primo entre la organización de voluntariado Western Sahara Campaign UK (WSC) ${ }^{5}$ y la Administración Fiscal y Aduanera, Reino Unido ${ }^{6}$ (Commissioners for Her Majesty's Revenu and Customs) y secundo entre WSC y el Ministerio de Medio Ambiente, Alimentación y Asuntos Rurales, Reino Unido (Secretary of State for Environment, Food and Rural Affairs) en relación con la aplicación por parte de dicha Administración Fiscal y el referido Ministerio de los acuerdos celebrados entre la Unión Europea y el Reino de Marruecos y de los actos de Derecho derivado vinculados con éstos ${ }^{7}$. Respaldando, por tanto, la competencia del TJUE en el marco de la petición de una decisión prejudicial para analizar la compatibilidad de los

2 Dicha decisión fue solicitada mediante una resolución de 27 de abril de 2016, que fue recibida en el Tribunal de Justicia el 13 de mayo de 2016.

${ }^{3}$ De conformidad con dicha disposición: "El Tribunal de Justicia de la Unión Europea será competente para pronunciarse, con carácter prejudicial: a) sobre la interpretación de los Tratados; b) sobre la validez e interpretación de los actos adoptados por las instituciones, órganos u organismos de la Unión. Cuando se plantee una cuestión de esta naturaleza ante un órgano jurisdiccional de uno de los Estados miembros, dicho órgano podrá pedir al Tribunal que se pronuncie sobre la misma, si estima necesaria una decisión al respecto para poder emitir su fallo. Cuando se plantee una cuestión de este tipo en un asunto pendiente ante un órgano jurisdiccional nacional, cuyas decisiones no sean susceptibles de ulterior recurso judicial de Derecho interno, dicho órgano estará obligado a someter la cuestión al Tribunal. Cuando se plantee una cuestión de este tipo en un asunto pendiente ante un órgano jurisdiccional nacional en relación con una persona privada de libertad, el Tribunal de Justicia de la Unión Europea se pronunciará con la mayor brevedad".

${ }^{4}$ Entre la numerosa bibliografía existente sobre la cuestión prejudicial, véase, R. ALONSO GARCÍA, "La cuestión prejudicial, piedra angular de la integración europea", European Inklings, no 4, 2014, pp. 9-28.

${ }^{5}$ La finalidad de WSC es fomentar el reconocimiento del derecho del pueblo del Sáhara Occidental a la libre determinación.

${ }^{6}$ En virtud de este primer procedimiento, la WSC solicitaba resolver si la Administración Fiscal y Aduanera estaba en condiciones de aceptar la importación al Reino Unido de productos procedentes del territorio del Sáhara Occidental certificados, a los efectos del Acuerdo de Asociación, como originarios del Reino de Marruecos. Vid. Sentencia del Tribunal de Justicia (Gran Sala) de 27 de febrero de 2018, párrafo 31.

7 Este segundo recurso cuestiona la política pesquera formulada por el Ministro de Medio Ambiente, Alimentación y Asuntos Rurales del Reino Unido al entender que supone la inclusión de las aguas adyacentes al territorio del Sáhara Occidental en el ámbito de aplicación de las medidas de Derecho interno cuyo objeto es la aplicación del Acuerdo de Colaboración, del Protocolo de 2013 y de los actos de Derecho derivado mediante los que la UE ha atribuido a los Estados miembros posibilidades de pesca en virtud del Acuerdo de Colaboración y del Protocolo de 2013. Vid. Sentencia del Tribunal de Justicia (Gran Sala) de 27 de febrero de 2018, op. cit., párrafo 31. 
acuerdos internacionales, celebrados por la $\mathrm{UE}^{\mathbf{8}}$, con los Tratados y con las normas de Derecho internacional que, en su virtud, vinculen a la UE ${ }^{9}$, incluidos los actos mediante los que la UE celebra dichos acuerdos, la petición de cuestión prejudicial se preguntaba sobre la validez del Acuerdo de Colaboración en el sector pesquero entre la Comunidad Europea y el Reino de Marruecos (en adelante, "Acuerdo de Colaboración") ${ }^{\mathbf{1 0}}$ aprobado y aplicado mediante: a) el Reglamento (CE) no 764/2006 del Consejo, de 22 de mayo de 2006, relativo a la celebración del Acuerdo de Colaboración; b) la Decisión 2013/785/UE del Consejo, de 16 de diciembre de 2013, relativa a la celebración, en nombre de la UE, del Protocolo entre la UE y el Reino de Marruecos ${ }^{\mathbf{1 1}}$ por el que se fijan las posibilidades de pesca y la contrapartida financiera establecidas en el Acuerdo de Colaboración ${ }^{\mathbf{1 2}}$; y d) mediante el Reglamento (UE) no $1270 / 2013$ del Consejo, de 15 de noviembre de 2013, relativo al reparto de las posibilidades de pesca en virtud del Protocolo entre la UE y el Reino de Marruecos ${ }^{\mathbf{1 3}}$. Más allá del cuadro que incluimos infra para una mayor clarificación de las normas convencionales discutidas (cuadro 1), huelga decir que el Acuerdo de Pesca, del que también forma parte el Protocolo 2018-2022, es un tratado que contribuye a los fines del Acuerdo de Asociación ${ }^{14}$ o "Acuerdo Euromediterráneo" de 2000. Las conclusiones del TJUE con respecto al ámbito territorial de aplicación de los tratados anteriores sobre la misma materia son, pues, importantes a la hora de

\footnotetext{
${ }^{8}$ Vid. Sentencia de 9 de agosto de 1994, Francia /Comisión, C-327/91, EU:C:1994:305, apartado 17; sentencia de 3 de septiembre de 2008, Kadi y Al Barakaat International Foundation/Consejo y Comisión, C-402/05 P y C-415/05 P, EU:C:2008:461, apartados 286 y 289.

${ }^{9}$ Vid. Dictamen 1/75 (Acuerdo OCDE -Norma sobre gastos locales), de 11 de noviembre de 1975. EU:C:1975:145, p. 1361.

${ }_{10}$ Vid. DO 2006, L 141, p. 4. El Acuerdo de Colaboración entró en vigor el 28 de febrero de 2007 (DO 2007, L 78, p. 31). Su objetivo busca consolidar las relaciones de cooperación establecidas entre la UE y el Reino de Marruecos, especialmente en el marco del Acuerdo de Asociación, mediante la creación en el sector pesquero de una colaboración cuya finalidad sea impulsar una pesca responsable en las zonas de pesca marroquíes y aplicar de manera eficaz la política pesquera de Marruecos.

${ }^{11}$ Vid. DO 2013, L 349, p.1.

12 El Protocolo de 2013 fue aprobado mediante Decisión 2013/785 y entró en vigor el 15 de julio de 2014 (DO 2014, L 228, p.1).

${ }^{13}$ Vid. DO 2013, L 328, p. 40.

${ }^{14}$ Se trata del Acuerdo Euromediterráneo por el que se crea una asociación entre las Comunidades Europeas y sus Estados miembros, por una parte, y el Reino de Marruecos, por otra. Dicho Acuerdo fue firmado en Bruselas el 26 de febrero de 1996 (DO 2000, L 70 , p. 2) y se aprobó en nombre de dichas Comunidades mediante Decisión 2000/204/CE, CECA, del Consejo y de la Comisión, de 24 de enero de 2000 (DO 2000, L 70, p. 1). El Acuerdo de Asociación entró en vigor el 1 de marzo de 2000, de conformidad con su artículo 96 . Vid. DO 2000, L 70, p. 228. Sobre los tratados sucesivos concernientes a la misma materia, véase el trabajo de la profesora A.G., LÓPEZ MARTÍN, "Aplicación de tratados sucesivos concernientes a la misma materia. Análisis del artículo 30 del Convenio de Viena de 1969 sobre Derecho de los Tratados", Anuario Colombiano de Derecho Internacional, vol. 10, 2017, pp. 51-84.
} 
valorar la dimensión espacial de dicho Acuerdo de Pesca y de su Protocolo de aplicación 2018-2022.

CUADRO 1

NORMAS CONVENCIONALES DISCUTIDAS

\begin{tabular}{|c|c|}
\hline $\begin{array}{l}\text { ACUERDO DE ASOCIACIÓN DE } \\
2000 \text { (ACUERDO } \\
\text { EUROMEDITERRÁNEO) }\end{array}$ & $\begin{array}{l}\text { OBJETIVO: Crear, por una parte, } \\
\text { una asociación entre las } \\
\text { Comunidades Europeas y sus } \\
\text { Estados miembros, y una } \\
\text { asociación, por otra, con el Reino } \\
\text { de Marruecos. ENTRADA EN } \\
\text { VIGOR: } 1 \text { de marzo de } 2000\end{array}$ \\
\hline $\begin{array}{l}\text { ACUERDO DE COLABORACIÓN DE } \\
2007 \text {. Este Acuerdo ha sido } \\
\text { acompañado, hasta la fecha, de } \\
\text { distintos Protocolos. El último, el } \\
\text { Protocolo 2018-2022, es el } \\
\text { resultado de la renegociación del } \\
\text { Protocolo de aplicación 2014- } \\
2018 \text { al Acuerdo de Colaboración } \\
\text { de } 2007\end{array}$ & $\begin{array}{l}\text { OBJETIVO: Consolidar las } \\
\text { relaciones de cooperación } \\
\text { establecidas entre la Unión } \\
\text { Europea y el Reino de Marruecos } \\
\text { con el fin de impulsar una pesca } \\
\text { responsable en las zonas de } \\
\text { pesca marroquíes (Preámbulo, } \\
\text { artículos } 1 \text { y } 3 \text { ). ENTRADA EN } \\
\text { VIGOR: } 28 \text { de febrero de } 2007\end{array}$ \\
\hline PROTOCOLO INICIAL 2007-2011 & $\begin{array}{l}\text { OBJETIVO: Fijar, para un período } \\
\text { de cuatro años, las posibilidades } \\
\text { pesqueras previstas en el } \\
\text { Acuerdo de Colaboración de } \\
2007 \text {. FECHA DE EXPIRACIÓN: } \\
14 \text { de diciembre de } 2011 \text {. }\end{array}$ \\
\hline
\end{tabular}

PROTOCOLO 2013 (en adelante, OBJETIVO: Fijar las posibilidades Protocolo 2014-2018)

de pesca y la contrapartida financiera prevista en el Acuerdo de Colaboración de 2007 y contribuir a la realización de los objetivos generales del Acuerdo de Asociación (artículo 1). ENTRADA EN VIGOR: 15 de julio de 2014. FECHA DE EXPIRACIÓN: 14 de julio de 2018.

PROTOCOLO 2018 (en adelante, OBJETIVO: Fijar, para un período Protocolo 2018-2022) de cuatro años, las posibilidades pesqueras previstas en el Acuerdo de Pesca. ENTRADA EN VIGOR: Primer trimestre de 2019.

A la luz de las argumentaciones mencionadas, el órgano jurisdiccional remitente -a saber, el referido Tribunal Superior de Justicia (Inglaterra y País de Gales), Sala de lo Contencioso-Administrativo, Reino Unidodecidió suspender el procedimiento y plantear al TJUE cuatro cuestiones 
prejudiciales relativas, las dos primeras, a la interpretación y validez del Acuerdo de Asociación, y las dos últimas a la validez del Acuerdo de Colaboración y de los distintos actos de Derecho derivado vinculados con el mismo.

Con respecto a la primera cuestión prejudicial, se trataba de concretar el ámbito de aplicación territorial del artículo 94 del Acuerdo de Asociación ${ }^{\mathbf{1 5}}$ y, muy especialmente, de precisar lo que se debía/debe entender por "territorio del Reino de Marruecos". ¿Comprende dicho territorio sólo el territorio soberano de ese Estado imposibilitando, por tanto, la importación a la UE de productos procedentes del territorio del Sáhara Occidental, exentos de derechos de aduana en virtud del Acuerdo?. Presumiendo que el Acuerdo de Asociación permitiera, en efecto, la importación de dichos productos, la segunda cuestión prejudicial se centraba en averiguar si dicho Acuerdo era válido a la luz del artículo 3 del Tratado de la Unión Europea (TUE), apartado 5 conforme al cual: "En sus relaciones con el resto del mundo, la Unión afirmará y promoverá sus valores e intereses y contribuirá a la protección de sus ciudadanos. Contribuirá a la paz, la seguridad, el desarrollo sostenible del planeta, la solidaridad y el respeto mutuo entre los pueblos, el comercio libre y justo, la erradicación de la pobreza y la protección de los derechos humanos, especialmente los derechos del niño, así como al estricto respeto y al desarrollo del Derecho internacional, en particular el respeto de los principios de la Carta de las Naciones Unidas". Dicho artículo fue invocado igualmente para fundamentar la tercera cuestión prejudicial sobre la validez del Acuerdo de Colaboración y de su tercer Protocolo de aplicación 2014-2018, es decir, el órgano jurisdiccional remitente solicitó al TJUE que aclarase en qué medida la UE estaba/está facultada para celebrar con el Reino de Marruecos acuerdos internacionales que permitan la explotación de los recursos naturales procedentes de las aguas adyacentes al territorio del Sáhara Occidental, especialmente si dichos acuerdos no respetan los deseos y/o no benefician los intereses del pueblo saharaui. Finalmente, la cuarta cuestión prejudicial intentaba resolver si la WSC estaba/está legitimada para impugnar la validez del Acuerdo de Asociación, del Acuerdo de Colaboración, del Protocolo 2014-2018 y de sus actos de celebración y aplicación ${ }^{\mathbf{1 6}}$.

Mediante sentencia de 21 de diciembre de $2016^{17}$, el TJUE declaró que el Acuerdo de Asociación no era aplicable al territorio del Sáhara

\footnotetext{
15 Según el artículo 94 del Acuerdo de Asociación: "El presente Acuerdo será aplicable, por una parte, en los territorios en los cuales se aplican los Tratados constitutivos de la Comunidad Europea y la Comunidad Europea del Carbón y del Acero y con arreglo a las condiciones establecidas en dichos Tratados $y$, por otra parte, en el territorio del Reino de Marruecos".

${ }^{16}$ Vid. Sentencia de 27 de febrero de 2018, op. cit., párrafos 35 a 38.

17 Vid. Sentencia de 21 de diciembre de 2016, Consejo/Frente Polisario, C-104/16 P, EU:C:2016:973. Para más información sobre esta sentencia del Tribunal, véase, E., DÍEZ PERALTA, "El Sáhara Occidental: una piedra en el camino de la asociación privilegiada
} 
Occidental ${ }^{18}$, razón por la que el Tribunal Superior de Justicia (Inglaterra y País de Gales), Sala de lo Contencioso-Administrativo, Reino Unido, acordó retirar sus dos primeras cuestiones prejudiciales, manteniendo vivas las dos últimas. De esta forma, presumiendo que el Acuerdo de Colaboración y el Protocolo 2014-2018, a pesar de la sentencia del TJUE de 2016, permiten la explotación de los recursos procedentes de las aguas adyacentes al territorio del Sáhara Occidental, esto es, al admitir que dichas aguas están incluidas en los respectivos ámbitos de aplicación de los tratados y que, en consecuencia, los buques de pabellón de un Estado miembro de la UE pueden acceder a las mismas para explotar sus recursos, la primera cuestión prejudicial (de las dos vivas) buscaba determinar la eficacia tanto del Reglamento no 764/2006 como de la Decisión 2013/785 y del Reglamento no 1270/2013; una comprobación que requería examinar, en todo caso, las disposiciones que precisan el alcance espacial de aplicación del Acuerdo de Colaboración de 2007 y del Protocolo 2014-2018, con el fin de comprobar si las aguas adyacentes al territorio del Sáhara Occidental están o no comprendidas en sus respectivos ámbitos territoriales. En cuanto a la cuestión de saber si la WSC está legitimada para impugnar la validez del Acuerdo de Asociación, del Acuerdo de Colaboración, del Protocolo 2014-2018 y de sus actos de celebración y aplicación, alegando el incumplimiento del Derecho internacional por parte de la UE, el TJUE no respondió a esta duda toda vez la respuesta ofrecida a la primera cuestión prejudicial (de las dos vivas).

\section{LA ACTUALIDAD DEL EL ESTATUTO JURÍDICO DEL SÁHARA OCCIDENTAL. UNA BREVE REFERENCIA.}

El Sáhara Occidental (antiguo Sáhara Español) es un territorio no autónomo ocupado del noroeste africano que limita al Norte con Marruecos, al Nordeste con Argelia, al Este y al Sur con Mauritania y al Oeste con el Océano Atlántico. En su calidad de territorio no autónomo, el Sáhara Occidental "tiene, en virtud de la Carta de las Naciones Unidas, una condición jurídica distinta y separada de la del territorio del Estado que lo administra, y esa condición (...) existirá hasta que el pueblo de la colonia o del territorio no autónomo haya ejercido su derecho de libre determinación de conformidad con la Carta" ${ }^{19}$. Desde esta perspectiva, constituye un lugar común que el Sáhara estuvo bajo administración española hasta 1976, año en el que, mediante el Acuerdo de Madrid de 1975, España transfirió la autoridad administrativa sobre el territorio saharaui a Marruecos y Mauritania, pero no la soberanía ni el estatus de potencia administradora. En otras palabras, la transmisión de la potestad

entre la UE y Marruecos", La Ley Unión Europea, no 46, marzo 2017, Ed. Wolters Kluwer, pp. 2-3.

${ }^{18}$ De esta suerte, el TJUE declaró que el Acuerdo de Asociación debía interpretarse de conformidad con las normas de Derecho internacional que vinculan a la UE.

19 Vid. Declaración sobre los Principios, Resolución 2625 (XXV) de la Asamblea General de la ONU, 1970. 
gestora no tuvo incidencia en la condición internacional del Sáhara Occidental como territorio no autónomo. Más aún, teniendo en cuenta que la integridad del territorio metropolitano no se extiende al territorio colonial, la presencia de la potencia colonizadora (España) sólo se entiende (entendía) aceptable en la medida en que garantice (garantizara) la administración del territorio colonial durante el período de transición a la plenitud del gobierno propio ${ }^{20}$. El Sáhara Occidental es, por tanto, una entidad que tiene un estatus internacional diferenciado del de la metrópoli (España, de iure), que incluye elementos asociados a los Estados soberanos. Así, por ejemplo, el respeto de la integridad del territorio de la colonia; el respeto del derecho del pueblo colonial a sus recursos naturales; el reconocimiento de los Movimientos de Liberación Nacional (MLN) como representantes de los pueblos coloniales (en nuestro caso, el Frente Polisario); y la consideración de que cualquier medida de fuerza o represiva de la autoridad administradora para impedir el ejercicio del derecho de libre determinación es contraria al principio de no intervención. Tras el acuerdo celebrado en 1979 entre Mauritania y el Frente Polisario, Mauritania se retiró del territorio, quedando sólo Marruecos como administrador del Sáhara ${ }^{21}$. Desde entonces, las reclamaciones de presuntos derechos o vínculos de soberanía territorial marroquíes sobre el Sáhara han sido rechazadas sistemáticamente por la Asamblea General de las Naciones Unidas ${ }^{22}$, la Organización de los

${ }^{20}$ El Sáhara Occidental fue un Protectorado español desde 1884. Incluido en la lista de "territorios no autónomos" con arreglo al Capítulo XI de la Carta de las Naciones Unidas (CNU), España -en su calidad de potencia administradora- transmitió, a partir de 1962, toda la información técnica y estadística sobre el territorio a la luz del artículo 73, apartado e) de la CNU. Mediante el Acuerdo de Madrid de 1975, España transfirió a Marruecos y a Mauritania sus facultades y responsabilidades (no la soberanía ni la condición de potencia administradora) sobre el territorio sin que esta transmisión afectara la condición internacional del Sáhara Occidental como territorio no autónomo. Debido a la complicada situación política interna que vivía España en aquel momento y a las fuertes presiones internacionales (la invasión por la llamada "Marcha Verde" o "Massira Al Khadra"), el 26 de febrero de 1976, España informó al entonces Secretario General de la ONU de que, con efectos a partir de esa fecha, ponía fin a su presencia en el Sáhara Occidental, renunciando a sus responsabilidades sobre el territorio y dejándolo de hecho bajo la administración de Marruecos y de Mauritania, en sus respectivos zonas de control. Vid. GOSALBO BONO, R., "El Frente Polisario, las normas del Derecho Internacional y el Derecho de la Unión Europea. Apuntes en torno a la Sentencia del Tribunal General, de 10 de diciembre de 2015, T-512/12, Frente Polisario/Consejo", Revista de Derecho Comunitario Europeo, núm. 53, enero/abril (2016), pp. 20-30, así como la extensa bibliografía citada por el autor en la nota a pie de página número 10 sobre el controvertido Estatuto del Sáhara Occidental; J.I., ALGUERÓ CUERVO, EI Conflicto del Sahara Occidental, desde una perspectiva canaria, Colección La Diáspora, Gobierno de Canarias, 2003, 550 pp.; T., BÁRBULO, La historia prohibida del Sáhara Español. Las claves del conflicto que condiciona las relaciones entre España y el Magreb, Ed. Península, 2017, 363 pp.; J., SOROETA LICERAS, El conflicto del Sáhara Occidental, reflejo de las contradicciones y carencias del Derecho Internacional, Universidad del País Vasco, Servicio Editorial 2001, 370 pp.

${ }^{21}$ Mauritania dejó de reclamar el Sáhara Occidental en 1979. Ese mismo año, la entonces Organización de la Unidad Africana (OUA) se sumó a la búsqueda de la Organización de las Naciones Unidas (ONU) de una solución pacífica para el conflicto.

${ }^{22}$ Vid. Resolución 3458 de 10 de diciembre de 1975. 
Estados Africanos ${ }^{23}$, por la propia CIJ en su Opinión Consultiva de $1975^{24}$, y por el Frente Popular para la Liberación de Saguía el-Hamra y de Río de Oro (Frente Polisario, 10 de mayo de $1973^{25}$ ), a saber, un MLN $^{26}$ que representa al pueblo saharaui y que goza de reconocimiento internacional ${ }^{27}$. Actualmente, la mayor parte del Sáhara Occidental está ocupado ilícitamente -mediante el recurso a la fuerza- por Marruecos, que lo considera parte integral de su territorio y que rechaza de plano la independencia de la antigua colonia española ${ }^{28}$. Empero, el Derecho internacional en vigor no admite la conquista como fundamento de un título de soberanía territorial, pues esta fórmula incurre en la prohibición taxativa de recurrir a la fuerza o la amenaza del uso de la fuerza en las relaciones internacionales (regulada en el artículo 2.4 . de la CNU y que, además, forma parte del Derecho internacional consuetudinario, tal y como declaró la CIJ en el asunto de las actividades militares y paramilitares en y contra Nicaragua, 1986). Éste es también, por ejemplo, el núcleo de la Resolución 242 (1967) del Consejo de Seguridad de la

\footnotetext{
${ }^{23}$ Vid. Resolución 103 (XVIII) de 24 de junio de 1981.

${ }^{24}$ Vid. Ibíd., Apartados 90-129.

${ }^{25}$ Sobre el contexto histórico e internacional en el que fue creado el Frente Polisario y la
} evolución posterior de la situación del Sáhara Occidental, véanse los párrafos 1 a 16 de la sentencia del Tribunal General de 10 de diciembre de 2015, Frente Polisario/Consejo (T-512/12, en lo sucesivo, «sentencia impugnada" que anuló parcialmente la Decisión 2012/497/UE del Consejo, de 8 de marzo de 2012, relativa a la celebración del Acuerdo en forma de Canje de Notas entre la Unión Europea y el Reino de Marruecos sobre medidas recíprocas de liberalización del comercio de productos agrícolas, productos agrícolas transformados, pescado y productos de la pesca, sustitución de los Protocolos no 1,2 y 3 y los anexos de estos Protocolos, y modificación del Acuerdo Euromediterráneo por el que se crea una Asociación entre las Comunidades Europeas y sus Estados miembros, por una parte, y el Reino de Marruecos, por otra, firmado en Bruselas el 26 de febrero de 1996 y aprobado en nombre de dichas Comunidades mediante la Decisión 2000/204/CE, CECA del Consejo y de la Comisión; J.C., GÓMEZ JUSTO, "El Frente Polisario: la historia de un Movimiento de Liberación Nacional", Revista Internacional de Pensamiento Político, 2013, vol. 8, pp. 261-280; C., JIMÉNEZ SÁNCHEZ, El conflicto del Sáhara Occidental: el papel del Frente Polisario, Capítulo X, II, A, Fundación Universitaria Andaluza, 2015, 230 pp.

${ }^{26}$ Vid. Artículo 1 de sus Estatutos

27 Los movimientos de liberación nacional son organizaciones formadas por la totalidad o parte de la población de un territorio sometido a dominación colonial, cuyo objetivo es la libre determinación de dicho territorio. Para que puedan gozar de personalidad jurídica internacional, es indispensable que la comunidad internacional se la reconozca y, aún así, dicha subjetividad internacional será limitada y de carácter funcional, es decir, básicamente destinada al ejercicio del derecho a la libre determinación.

${ }^{28}$ Marruecos no figura como potencia administradora del territorio del Sáhara Occidental en la lista de territorios no autónomos de las Naciones Unidas ya que, de iure, esa potencia administradora sigue siendo España, siendo esa precisamente la razón por la que Marruecos no ha facilitado la información sobre el territorio prevista en el artículo 73, apartado e) de la CNU. Más aún, Marruecos considera que no tiene por qué transmitir dicha información en el entendido de que es él quien tiene vínculos de soberanía sobre el Sáhara Occidental, formando éste parte de su territorio. Vid. GOSALBO BONO, R., "Frente Polisario, las normas del Derecho internacional y el Derecho de la Unión Europea. Apuntes en torno a la sentencia del Tribunal General, de 10 de diciembre de 2015, T512/12, Frente Polisario/Consejo", op. cit., p. 30. 
ONU, que declara la ilegalidad de la ocupación israelí de los altos del Golán, la franja de Gaza, Cisjordania y Jerusalén Oriental ${ }^{29}$. Por otro lado, la parte más pequeña y menos poblada, situada al Este, se encuentra bajo el control del Frente Polisario ${ }^{30}$ cuyo fundamento jurídico es el reconocimiento del derecho de autodeterminación del último territorio africano "no autónomo", en el sentido del artículo 73 de la Carta de las Naciones Unidas (CNU) ${ }^{31}$. De esta suerte, varias décadas después del Plan de Paz de $1991^{32}$-en el que se prevé el referéndum de autodeterminación del pueblo saharaui- la realidad de una consulta en condiciones homologables no parece muy cercana. Precisamente en este escenario complejo es en el que hoy tiene que desenvolverse el alemán Horst Köhler, nuevo enviado del Secretario General de la Organización de las Naciones Unidas (ONU), António Guterres, para tratar de avanzar en el conflicto y para evitar que éste se perpetúe "hasta el final de los tiempos", según afirma el Rey alauí Mohamed VI. Pues si recordamos su discurso de El Aaiún de 2015, pronunciado con motivo del $40^{\circ}$ aniversario de la Marcha Verde, lo máximo que Marruecos está dispuesto a conceder actualmente (con el apoyo inter alia de los Estados Unidos de América, de Francia y ¿últimamente de España?) $)^{33}$ es un estatuto de autonomía pero no un referéndum de autodeterminación, lo que contraría abiertamente la

${ }^{29}$ Vid. A. REMIRO BROTONS, R.M. RIQUELME CORTADO, E. ORIHUELA CALATAYUD, J. DÍEZ-HOCHLEITNER, L.PÉREZ-PRAT DURBÁN, Derecho Internacional, Ed. McGrawHill, 1997, p. 526. En adelante haremos referencia a esta obra como A. REMIRO BROTONS, et al., Derecho Internacional.

${ }^{30}$ El territorio controlado por el Frente Polisario está separado del territorio controlado por el Reino de Marruecos por un muro de arena construido por este último y vigilado por el ejército marroquí. Un número importante de refugiados procedentes del Sáhara Occidental vive en campos gestionados por el Frente Polisario, situados en territorio argelino, en la zona conocida como Queltat Zemur, cerca del Sáhara Occidental.

31 Un territorio no autónomo es un territorio dependiente que, por mandato de la Organización de las Naciones Unidas, debe ser objeto de un proceso de descolonización. Actualmente todavía existen diecisiete territorios no autónomos. De acuerdo con el artículo 73 de la Carta de las Naciones Unidas (incluido en el Capítulo XI titulado "Declaración relativa a territorios no autónomos"): "Los Miembros de las Naciones Unidas que tengan o asuman la responsabilidad de administrar territorios cuyos pueblos no hayan alcanzado todavía la plenitud del gobierno propio, reconocen el principio de que los intereses de los habitantes de esos territorios están por encima de todo, aceptan como un encargo sagrado, la obligación de promover en todo lo posible, dentro del sistema de paz y de seguridad internacionales establecido por esta Carta, el bienestar de los habitantes de esos territorios (...)".

32 Aunque el 26 de febrero de 1976, España renunció a sus obligaciones de carácter internacional relativas a la administración del Sáhara Occidental, para la ONU sigue siendo la potencia administradora (y Marruecos la potencia ocupante). Vid. Conclusiones del Abogado General Sr. Melchor Wathelet, presentadas el 13 de septiembre de 2016 (1), Asunto C-104/16 P, Consejo de la Unión Europea contra Frente Popular para la Liberación de Saguía el Hamra y Río de Oro (Frente Polisario), p. 16, párrafo 187.

33 Vid. J. GONZÁLEZ VEGA, "El Sáhara Occidental, de nuevo, en Luxemburgo", La Ley Unión Europea, no 56, 2018, p. 40; del mismo autor "A Bridge over Troubled Waters (and Sands). A critical Sight on Spain's Role in Western Sahara", Spanish Yearbook of International Law, 20, 2016, pp. 255-277; I., FERNÁNDEZ MOLINA, Moroccan Foreign Policy under Mohammed VI, Durham Modern Middle East and Islamic World East Series, London and New York, Routledge, 2016, Xvi +, 260 pp. 
literalidad de las Resoluciones del Consejo de Seguridad de la ONU a estos efectos ${ }^{34} y$, en particular, el párrafo segundo de la Resolución 690 (1991) de 29 de abrill ${ }^{35}$.

Marruecos considera que el Sáhara forma parte de su territorio y, a su entender, la aplicación territorial de los tratados de los que forma parte debe extenderse a todo su espacio físico, ya sea terrestre, aéreo o marítimo. En efecto, entre sus últimas iniciativas, el reino alauí ha celebrado con la UE un Acuerdo de Pesca y un nuevo Protocolo de aplicación 2018-2022 que, a nuestro juicio, no respetan: a) la integridad territorial del Sáhara, ya que Marruecos dispone de unos recursos vivos que no están bajo su soberanía; b) conculcan el derecho del pueblo saharaui a sus riquezas naturales, pues no queda claro ni confirmado que la explotación de esos recursos beneficie efectivamente a dicho pueblo ni que se les haya consultado previamente al respecto; c) cuestionan el reconocimiento del Frente Polisario como representante del pueblo colonial, en la medida en que, por ejemplo, mientras Marruecos aceptó la validez del acuerdo entre Mauritania y el Frente Polisario de 1979, mediante el que Mauritania puso fin a su coautoridad administrativa del territorio, en el caso de los últimos tratados de pesca con la UE, tanto para la UE como para Marruecos, sólo Marruecos ha sido (es) el interlocutor válido para ejercer el ius ad tractatum, esto es, una de las manifestaciones de la personalidad jurídica internacional que poseen (en distinto grado) los sujetos de Derecho internacional, entre los que se incluyen los MLN, como el Frente Polisario, si bien la práctica no es uniforme o puede resultar controvertida a este respecto; y, por último, la ocupación militar del Sáhara por parte de Marruecos para privar al pueblo saharaui de su identidad constituye una violación de sus derechos inalienables y del principio de no intervención, a la luz v.g. de distintas resoluciones de la Asamblea General de la ONU como, por ejemplo, las resoluciones 2131 (XX), 2160 (XXI), 2625 (XXV) o 3314 (XXIX).

\section{EL ACUERDO DE PESCA Y SU PROTOCOLO DE APLICACIÓN 2018-2022}

Como hemos advertido en las primeras páginas de este trabajo, el Acuerdo de Colaboración de 2007 se inscribe en el marco de las relaciones entre la UE y Marruecos, tal y como se desprende del Acuerdo Euromediterráneo o de Asociación, de 26 de febrero de 1996, por el que

\footnotetext{
34 Para más información sobre las claves históricas del conflicto, véase, J. SOROETA LICERAS, "La sentencia de 10 de diciembre de 2015 del Tribunal General de la UE (T512/12), primer reconocimiento en vía judicial europea del estatuto del Sahara Occidental y de la subjetividad internacional del Frente Polisario" (RI §417010), Revista General de Derecho Europeo, no 38, 2016.

${ }^{35}$ Sobre las expectativas marroquíes sobre el Sáhara Occidental, véase el "Informe del Secretario General sobre la situación relativa al Sáhara Occidental", (S/2017/307), de 10 de abril de 2017, pp. 4 y 5; R. BARREÑADA, I., y OJEDA, Sáhara Occidental. 40 años después, Madrid, Los Libros de la Catarata, 2016, 320 páginas.
} 
se crea una asociación entre las Comunidades Europeas y sus Estados miembros, por una parte, y el Reino de Marruecos, por otra, que entró en vigor en 2000. Su objeto consiste en garantizar la buena gestión y la sostenibilidad de los recursos pesqueros desde el punto de vista ecológico, económico y social. En vigor desde el 28 de febrero de 2007, el Acuerdo se aplicó mediante dos Protocolos sucesivos que permitían a los buques de la UE que pescan especies pelágicas ${ }^{36}$ y demersales ${ }^{37}$ acceder a la zona pesquera de Marruecos hasta el 14 de diciembre de 2011, fecha que determinó la rescisión del segundo Protocolo de aplicación toda vez que el Parlamento Europeo se opuso a su celebración al cuestionar su sostenibilidad, rentabilidad y legalidad internacional. El tercer Protocolo 2014-2018, celebrado en 2014 y que expiró el 14 de julio de $2018^{38}$, precisamente "tuvo en cuenta las preocupaciones reveladas en su momento por el Parlamento Europeo". Basándose en las directrices pertinentes adoptadas por el Consejo (de Agricultura y Pesca), de 16 de abril de 2018, la Comisión Europea propuso al Gobierno de Marruecos la negociación de un nuevo Acuerdo de Colaboración (el llamado "Acuerdo de Pesca") y de un nuevo Protocolo de aplicación 2018-2022. Sin embargo, como hemos tenido ocasión de comentar, estas negociaciones se alejan de la jurisprudencia más reciente del TJUE en la materia y no cuestionan, en modo alguno, la capacidad de Marruecos para celebrar este tipo de tratados.

Tomando como referencia estas premisas, en este epígrafe intentaremos analizar, desde una perspectiva crítica, los siguientes extremos: a) la sentencia del TJUE, en el caso C-266/16, con el fin de evaluar si realmente excluye las aguas saharauis del ámbito de aplicación territorial del Acuerdo de Colaboración de 2007 y de su Protocolo 2014-2018 y, por ende, valorar cuál ha sido su incidencia en el nuevo Acuerdo de Pesca y su Protocolo de aplicación 2018-2022, pues estos tratados también contribuyen a sus fines $y$, por consiguiente, a los del Acuerdo de Asociación o Acuerdo Euromediterráneo de 2000; b) la concreta aplicación territorial del Acuerdo de Pesca y de su Protocolo 2018-2022; c) si la celebración de estos tratados respeta el derecho del pueblo colonial a sus

\footnotetext{
${ }^{36}$ Las especies pelágicas viven en aguas medias o cerca de la superficie limitando al máximo su contacto con el fondo marítimo o la costa. Por ejemplo, la sardina, la anchoa o el cachalote.

37 Las especies demersales son peces que viven cerca del fondo del mar o lagos. Pueden ser: a) bentónicos (aquéllos que viven constantemente sobre el fondo del lecho marino; b) bentopelágicos (aquéllos que nadan por encima del fondo).

${ }^{38}$ El Protocolo 2014-2018 entre la UE y Marruecos permite el acceso a un máximo de 126 buques de la UE a la zona de pesca de Marruecos en el Atlántico a cambio de una contrapartida financiera por parte de la UE de 30 millones EUR anuales, de los cuales 16 millones EUR justifican la compensación financiera por el acceso a los recursos y 14 millones EUR van destinados a apoyar a la política del sector pesquero de Marruecos. A estas cantidades hay que añadir una contribución de los armadores de la UE de 10 millones EUR, en su condición de beneficiarios de las licencias de pesca expedidas. Los arrastreros pelágicos de la categoría 6 (91\% de los cánones) y los arrastreros demersales de la categoría $4(5 \%)$ son los principales contribuyentes.
} 
recursos naturales (pesqueros); y d) las razones por las que, a pesar de los problemas jurídicos existentes, la UE y Marruecos han decidido adoptar estos nuevos tratados.

\subsection{La sentencia del TJUE, de 27 de febrero de 2018 , en el caso C- 266/16}

Como es sabido, la sentencia del TJUE, de 27 de febrero de 2018, en el asunto C-266/16, declaró que el ámbito espacial del Acuerdo de Colaboración de 2007 y de su Protocolo de aplicación 2014-2018 no alcanza a las zonas adyacentes al territorio del Sáhara Occidental. Por lo tanto, la aplicación territorial del Acuerdo de Pesca y de su Protocolo de aplicación 2018-2022 tendría que haber respetado esa decisión. Sin embargo, aunque parezca que la última decisión del Tribunal es coherente y conforme con su jurisprudencia anterior, lo cierto es que, en el caso del Sáhara Occidental, el TJUE ha aplicado una diferente "vara de medir"39 que, a la postre, ha facilitado a la Comisión Europea la negociación de unos acuerdos que se alejan de la jurisprudencia (en este caso ambigua) del TJUE, y que incluso puede mermar la credibilidad de la Unión Europea. Así, mientras en el asunto Brita $(\mathrm{C}-386 / 08)^{40}$, el órgano judicial interpretó el ámbito de aplicación territorial del Acuerdo entre la UE e Israel a la luz del principio pacta tertiis nec nocent nec prosunt ${ }^{41}$ (del que el artículo 34 del Convenio de Viena sobre el Derecho de los Tratados constituye una expresión concreta), excluyendo los productos originarios de Cisjordania del ámbito de aplicación del Acuerdo con Israel, y especificando que las mercancías israelíes fabricadas en territorios palestinos ocupados no pueden beneficiarse del régimen preferencial aduanero previsto en el acuerdo, toda vez el carácter distinto del territorio de Israel y los territorios ocupados, en el presente asunto, siendo una situación muy similar a la de la empresa alemana Brita, el Tribunal afirma que el Sáhara Occidental no forma parte del territorio de Marruecos pero no excluye sus productos originarios al entender, gracias a una pirueta jurídico semántica, que el objetivo del último Acuerdo entre la UE y el Reino de Marruecos no es un acuerdo de asociación relativo a las mercancías

\footnotetext{
${ }^{39}$ En este sentido, véase el estudio del Embajador de Argelia en Bruselas, A. BELANI, "L'UE et son doublé standard sur le statut des territoires occupés", http://www.algeriepatriotique.com/article/contribution; OANTA, G.A., "Tres sentencias claves para la delimitación del contorno jurídico de las competencias convencionales de la Unión Europea en el ámbito pesquero", en Revista de Derecho Comunitario Europeo, no 53, 2016, pp. 201-231; J., ROLDÁN BARBERO, "La aplicación territorial del Derecho de la Unión Europea y el Derecho Internacional", Revista de Derecho Comunitario Europeo, núm. 51, 2015, pp. 453-490; D., SIMON, A., RIGAUX, "Le Tribunal et le Droit international des traités: un arrêt déconcertant (Tribunal de I'Union Européenne, 10 décembre 2015, affaire T-512/12, Front Polisario c/ Conseil soutenu par la Commission", LexisNexis, Europe, núm. 2, Février 2016.

${ }^{40}$ Vid. Sentencia de 25 de febrero de 2010, Brita, C-386/08, EU:C:2010:91.

${ }^{41}$ En virtud del principio pacta tertiis nec nocent nec prosunt, el acuerdo concluido entre Israel y la Unión Europea no podía afectar a terceros (es decir, a la OLP) por haber concluido la UE un acuerdo de asociación con la OLP aplicable en Gaza y Cisjordania.
} 
procedentes del Sáhara Occidental. ¿Hubiera resuelto el Tribunal de igual modo en el caso de que la UE hubiera celebrado un Acuerdo de Asociación con el Frente Polisario, especificando su aplicación al "territorio del Sáhara Occidental"?. Y en este supuesto, ¿no habría tenido que exigir el TJUE como sí hizo en el caso palestino-israelí- el etiquetado de la pesca procedente de las aguas saharauis (que forman parte del territorio del Sáhara Occidental) para indicar claramente su origen ${ }^{42}$ ?. En este sentido, toda vez que la Organización de las Naciones Unidas (ONU) utiliza un Código de País para el Sáhara Occidental (732 ESH EH ISO 3166-2) distinto del Código de País asignado a Marruecos (504 MAR MA ISO 31662 ), dicha distinción podría servir de base para establecer reglas de origen adecuadas para los productos procedentes de ese territorio no autónomo. A nuestro juicio, por medio de su última sentencia, el TJUE serpentea la dificultad legal en la que se habrían encontrado los órganos judiciales de los Estados miembros de la UE a la hora de respetar el contenido de su decisión prejudicial. En otras palabras, si el TJUE hubiera excluido la explotación de los recursos de las aguas saharauis, la UE no habría podido importar tales productos pues, como es sabido, las decisiones sobre cuestiones prejudiciales son obligatorias tanto para el órgano jurisdiccional remitente como para los Tribunales de los Estados miembros de la UE.

\subsection{El alcance espacial del Acuerdo de Pesca y del Protocolo 2018- 2022 según el Derecho de los tratados}

El 24 de julio de 2018 se rubricaron el Acuerdo de Colaboración de Pesca Sostenible entre la UE y el Reino de Marruecos (el "Acuerdo de Pesca", que sustituye al Acuerdo de 2007), su nuevo Protocolo de aplicación 2018-2022, un anexo, apéndices, y un canje de notas. De conformidad con lo dispuesto en el artículo 16 del Protocolo 2018-2022, el tratado abarca un período de cuatro años a partir de su fecha de entrada en vigor. De ahí que nos refiramos a él como Protocolo 2018-2022. Teniendo en cuenta que no se ha activado la aplicación provisional del tratado, su aplicación está supeditada a su entrada en vigor, prevista para el primer trimestre de 2019. Como es sabido, en el marco de la UE, el texto debe contar con la aprobación del Consejo y del Parlamento Europeo. Pues bien, presumiendo la existencia del tratado (a través de su próxima publicación y registro), procede examinar si el Acuerdo de Pesca y su

42 Cf. E. DÍEZ PERALTA, "Made in Israel": Reflexiones en torno al etiquetado de mercancías fabricadas en los territorios palestinos ocupados. A propósito de la Sentencia Brita del Tribunal de Justicia de la Unión Europea, de 25 de febrero de 2010 (C-386/08)", Revista General de Derecho Europeo, no21, 2010, p. 9; C (2015) 7834 final, Interpretative Notice on Indication of origin of godos from the territories occupied by Israel since June 1967 (11.11.2015); C., TEIJO GARCÍA, "Una aproximación a la práctica convencional de los acuerdos de asociación pesquera suscritos por la Comunidad Europea", en PUEYO LOSA, J. JORGE URBINA, J., (Coordinadores), La cooperación internacional en la ordenación de los mares y océanos, Ed. Iustel, Madrid, 2009, pp. 263291. 
Protocolo de aplicación 2018-2022 son aplicables en el Sáhara Occidental, esto es, corresponde determinar el alcance espacial o ámbito de aplicación territorial de los tratados.

Si nos atenemos a lo dispuesto en el artículo 31, apartado 1 del Convenio de Viena de 1969 sobre Derecho de los Tratados, un instrumento que vincula a las instituciones de la UE como expresión de una norma de Derecho internacional general que forma parte del ordenamiento jurídico comunitario, "un tratado deberá interpretarse de buena fe conforme al sentido corriente que haya de atribuirse a los términos del tratado en el contexto de éstos y teniendo en cuenta su objeto y fin". Según su párrafo 2, "para los efectos de la interpretación de un tratado, el contexto comprenderá, además del texto, incluidos su preámbulo y anexos (...) todo acuerdo que se refiera al tratado y haya sido concertado entre todas las partes con motivo de la celebración del tratado". Por lo tanto, el contexto comprende el Protocolo 2014-2018 que, aunque ya no está en vigor, es un tratado posterior sobre la misma materia celebrado entre las mismas partes. Más aún, el artículo 31, inciso 3, del mismo Convenio también obliga a tomar en consideración "todo acuerdo ulterior entre las partes acerca de la interpretación del tratado o de la aplicación de sus disposiciones". Por consiguiente, para interpretar el ámbito de aplicación del Acuerdo de Pesca hace falta tener en cuenta las disposiciones pertinentes del Protocolo 2018-2022.

A diferencia del Acuerdo de Colaboración de 2007 y de su Protocolo de aplicación 2014-2018, que en ninguna de sus disposiciones mencionan expresamente al Sáhara Occidental ${ }^{43}$, pero a cuyo territorio sí se extienden espacialmente, tanto el nuevo Acuerdo de Pesca como su Protocolo 2018-2022 sí lo hacen, sobre la base, principalmente, de la importancia económica que ambos tratados representan para la UE y para Marruecos, y a tenor de los presuntos beneficios materiales y sociales que esos textos pueden generar para el "pueblo saharaui". Llegados a este punto, el Derecho de los Tratados y, más en concreto, el artículo 29 del Convenio de Viena de 1969 dispone, con respecto al ámbito espacial de las normas convencionales, que: "un tratado será obligatorio para cada una de las partes por lo que respecta a la totalidad de su territorio, salvo que una intención diferente se desprenda de él o conste de otro modo". ¿Y qué debe entenderse por "territorio"?. Según el Derecho internacional, el territorio de un Estado comprende su espacio terrestre, sus aguas

\footnotetext{
${ }^{43}$ En efecto, si examinamos el artículo 11 del Acuerdo de Colaboración de 2007, el ámbito territorial de aplicación del tratado se extiende, por lo que se refiere al Reino de Marruecos, al "territorio de Marruecos y a las aguas bajo jurisdicción marroquí". Por su parte, el artículo 2, letra a) del mismo texto define los términos "zona de pesca marroquí", en la que se efectúa la explotación pesquera a la que alude dicho Acuerdo, como "las aguas bajo soberanía o jurisdicción del Reino de Marruecos". Finalmente, en lo que atañe más en concreto a las actividades pesqueras, el artículo 5 de ese Acuerdo establece que se autorizará a los buques que enarbolen pabellón de un Estado miembro "el ejercicio de actividades pesqueras en (las) zonas de pesca (del Reino de Marruecos)".
} 
interiores, el mar territorial (así como las aguas archipelágicas, en el caso de un Estado archipelágico) y el espacio aéreo suprayacente a estas zonas. Teniendo en cuenta estos datos, así como la jurisprudencia del TJUE anterior a su sentencia de 27 de febrero de 2018, en virtud de la cual, el territorio de Marruecos es el espacio geográfico en el que el Reino de Marruecos ejerce la plenitud de aquéllas de sus competencias que reconoce a las entidades soberanas el Derecho internacional, con exclusión de cualquier otro territorio, como puede ser el del Sáhara Occidental ${ }^{44}$, es obvio que ni el nuevo Acuerdo de Pesca ni su Protocolo de aplicación 2018-2022, deberían aplicarse en el territorio saharaui. En otras palabras, la presunción de territorialidad no opera en los territorios no autónomos que estén bajo la administración de un Estado (Marruecos), ni tampoco en los territorios ocupados por un Estado mediante el recurso a la fuerza, como es también el caso de la ocupación marroquí del Sáhara. Con respecto a los territorios no autónomos, como regla general ha de entenderse que los tratados concluidos por un Estado no se extienden de pleno derecho a estos territorios que, aun estando bajo su administración, no son de su soberanía y tienen una condición jurídica perfectamente diferenciada. De ahí que el artículo 29 del Convenio de Viena de 1969 sobre Derecho de los Tratados hable de "territorio de las partes" y no del "territorio del que internacionalmente sean responsables". Por otro lado, en el territorio ocupado sólo procede la aplicación de los tratados concluidos por el ocupante que específicamente tengan que ver con el hecho de la ocupación derivada de un conflicto bélico o similar. En este contexto, habiéndose anexionado unilateralmente el Sáhara, Marruecos no considera que el territorio esté ocupado. Lo que Marruecos afirma es que el Sáhara Occidental está bajo su soberanía y, en consecuencia, las aguas adyacentes al mismo están subsumidas en los respectivos ámbitos de aplicación del Acuerdo de Pesca y de su Protocolo de aplicación 20182022. Lo que busca, en definitiva, es la aplicación (también en el Sáhara) de los tratados de los que sea parte. A mayor abundamiento, el hecho de que los últimos textos incluyan el territorio y las aguas adyacentes del Sáhara Occidental en sus respectivos ámbitos de aplicación espacial supone una vulneración, a nuestro juicio, de determinadas normas de Derecho internacional general que son aplicables a las relaciones de la UE con el Reino de Marruecos ${ }^{45}$. Así, el referido artículo 29 del Convenio de Viena de 1969 sobre Derecho de los Tratados, que regula su aplicación territorial; y el artículo 34 del mismo texto que establece que los tratados no deben perjudicar ni beneficiar a terceros sin su consentimiento. Más aún, tal y como declaró la CIJ en los párrafos 121 y 122 de su opinión consultiva relativa a la construcción de un muro en el territorio palestino ocupado, "la anexión de un territorio cuyo pueblo goza del derecho a la libre determinación cuando dicho pueblo aún no haya ejercido tal derecho constituye un incumplimiento de la obligación de respetar ese mismo

\footnotetext{
44 Vid. Sentencia, de 21 de diciembre de 2016, Consejo/Frente Polisario, C-104/16, EU:C:2016:973, apartados 95 y 132.

${ }^{45}$ Vid. Ibíd., párrafos 88 a 93, 100, 103 a 107 y 123.
} 
derecho"46. A la luz, asimismo, del artículo 4 del Protocolo Adicional I, el artículo 47 del IV Convenio de Ginebra o del laudo arbitral, de 18 de abril de 1925 , en el asunto relativo a la deuda pública otomana ${ }^{47}$, al celebrar un acuerdo internacional aplicable al territorio ocupado, la potencia ocupante (Marruecos) debe actuar en calidad de potencia ocupante y no como soberano del territorio ocupado (Sáhara Occidental), pues la anexión del territorio ocupado está estrictamente prohibida ${ }^{48}$.

\subsection{El "respeto" del derecho del pueblo colonial a sus recursos naturales (pesqueros)}

Por otro lado, aunque se trata de una cuestión controvertida ${ }^{49}$, parece que ni el Derecho internacional consuetudinario, ni la jurisprudencia y prácticas internacionales, ni el Derecho de la Unión Europea prohíben categóricamente la celebración de tratados que afecten a territorios ocupados $^{50}$ siempre que, como hemos visto, la potencia ocupante se comporte como tal y no como soberana del territorio ocupado. Así se desprende, por ejemplo, del Dictamen del año 2002 del asesor jurídico de la ONU, Hans Corell, al Consejo de Seguridad de la ONU ${ }^{51}$, de varias sentencias de la Corte Internacional de Justicia como las emitidas en el asunto relativo a Timor Oriental (Portugal v. Australia) ${ }^{52}$ y en el asunto sobre Ciertas Tierras Fosfáticas en Nauru (Nauru v. Australia) ${ }^{53}$, o de la sentencia del Tribunal de Primera Instancia (Sala Primera), de 6 de julio de 1995, en el asunto T-572/93, Odigitria AAE c. Consejo de la Unión Europea y Comisión de las Comunidades Europeas ${ }^{54}$ en el que se constató que las instituciones de la UE "gozan de una amplia facultad de

\footnotetext{
${ }^{46}$ Vid. Consecuencias jurídicas de la construcción de un muro en el territorio palestino ocupado, Opinión Consultiva, CIJ Recueil, 2004, p. 136.

47 Vid. Asunto relativo a la deuda pública otomana (Bulgaria, Iraq, Palestina, Transjordania, Grecia, Italia y Turquía), Recueil des sentences arbitrales, vol. 1, pp. 259 a 614.

48 Vid. L. OPPENHEIN, "The Legal Relations between and Occupying Power and the Inhabitants", Law Quarterly Review, 1917, vol. 33, pp. 363 y 364; Y. DINSTEIN, The International Law of Belligerent Occupation, Cambridge University Press, Cambridge, 2009, pp. 49 a 51; É. DAVID, Principes de droit des conflicts armés, 5a ed. Bruylant, Bruselas, 2012, pp. 582 y 583; M. BOTHE, "The Administration of Occupied Territory", en A. Clapham, P. Gaeta y M. Sassòli (eds.), The 1949 Geneva Conventions: A Commentary, Oxford University Press, Oxford, 2015, pp. 1455 a 1484, apartado 10.

${ }^{49}$ Cfr. J., SOROETA LICERAS, "La sentencia de 10 de diciembre de 2015 del Tribunal General de la UE (T-512/12), primer reconocimiento en vía judicial europea del estatuto del Sahara Occidental y de la subjetividad internacional del Frente Polisario", op. cit., p. 17.

50 Vid. R., GOSALBO BONO, "El Frente Polisario, las normas del Derecho Internacional y el Derecho de la Unión Europea. Apuntes en torno a la Sentencia del Tribunal General, de 10 de diciembre de 2015, T-512/12, Frente Polisario/Consejo", op. cit., pp. 56-57, así como la bibliografía especificada en las notas a pie de página números 95 a 97.

${ }^{51}$ Vid. Documento S/2002/161, de 12 de febrero de 2002.

52 Vid. Timor Este (Portugal v. Australia), sentencia de 30 de junio de 1995, ICJ, Reports 1995 , p. 90.

53 Vid. Ciertas Tierras Fosfáticas en Nauru (Nauru v. Australia), Ordenanza de 13 de septiembre de 1993, ICJ, Reports 1993, p. 322.

54 Vid. European Court Reports 1995 II-02025.
} 
apreciación, tanto en el ámbito de las relaciones económicas exteriores (...) como en el ámbito interno (...)" que, en cualquier caso, no escapa al control jurisdiccional del juez de la UE (artículo 263 TFUE) ${ }^{55}$. Si nos situamos en la negociación del Acuerdo de Pesca y de su Protocolo de Aplicación 2018-2022 ${ }^{56}$ (acuerdo multi-especies ${ }^{57}$ ) resulta que, a la luz de esa amplia facultad de apreciación de las instituciones de la UE, la Comisión Europea ${ }^{58}$ no ha considerado in toto la sentencia del TJUE (Gran Sala), de 27 de febrero de $2018^{59}$, con respecto a la eventualidad de excluir del acuerdo con Marruecos el territorio del Sáhara Occidental (incluidas sus aguas adyacentes $\mathrm{y}$, por ende, los productos procedentes de las mismas), contradiciéndose con argumentos del pasado ${ }^{60}$ cimentados, en esencia, en la Resolución 2625 (XXV) de 1970 de la Asamblea General de la ONU. En efecto, si nos fijamos en las directrices de negociación del Protocolo 2018-2022, de enero de 2018 ${ }^{61}$, uno de los objetivos de la Comisión fue garantizar el acceso a aguas bajo la soberanía o la jurisdicción del Reino de Marruecos por lo que respecta a la pesca -es decir, incluyendo las aguas al sur de $27040^{\prime} \mathrm{N}-$ y las autorizaciones necesarias para que los buques de la flota de la UE faenaran en esas

55 De conformidad con el artículo 263 del TFUE, "El Tribunal de Justicia de la Unión Europea controlará la legalidad de los actos legislativos, de los actos del Consejo, de la Comisión y del Banco Central Europeo (...). A tal fin, el Tribunal de Justicia de la Unión Europea será competente para pronunciarse sobre los recursos por incompetencia, vicios sustanciales de forma, violación de los Tratados o de cualquier otra norma jurídica relativa a su ejecución, o desviación de poder, interpuestos por un Estado miembro, el Parlamento Europeo, el Consejo o la Comisión (...)".

56 La negociación de un Protocolo de pesca con el Reino de Marruecos está en consonancia con la acción exterior de la UE respecto a sus países vecinos (artículo 218 del TFUE, quinta Parte (Acción Exterior de la UE), título V (acuerdos internacionales), que establece el procedimiento para la negociación y celebración de acuerdos entre la Unión y terceros países, y es conforme con los objetivos de la Unión relativos al respeto de los principios democráticos y los derechos humanos. Las negociaciones se llevan a cabo, a lo largo de todo el proceso, en consulta con todos los servicios interesados de la Comisión, con el SEAE y con la ayuda de la Delegación de la UE competente. Por otro lado, tanto el artículo 21.2.c) del TUE como el Preámbulo del TFUE se refieren a la Carta de las Naciones Unidas como el instrumento jurídico que informa toda la acción exterior de la UE.

57 El Protocolo permite el acceso a diferentes tipos de recursos incluyendo pequeños pelágicos tanto al norte como al sur, algunas especies demersales y especies altamente migratorias.

58 Vid. Artículo 1 de la Decisión del Consejo por la que se autoriza a la Comisión a entablar negociaciones en nombre de la UE para la celebración del Protocolo de aplicación del Acuerdo de colaboración en el sector pesquero con el Reino de Marruecos, COM (2018) 1 final, Bruselas, 8 de enero de 2018.

${ }^{59}$ Como es sabido, la decisión sobre una cuestión prejudicial es obligatoria tanto para el órgano jurisdiccional remitente como para los Tribunales de los Estados miembros de la UE.

${ }^{60}$ Vid. T-512/12, Frente Polisario vs. Consejo.

61 Vid. Recomendación de Decisión del Consejo por la que se autoriza a la Comisión a entablar negociaciones en nombre de la Unión Europea para la celebración del Protocolo de aplicación del Acuerdo de colaboración en el sector pesquero con el Reino de Marruecos. Anexo. Directrices de negociación, COM(2018) 1 final, Bruselas 8 de enero de 2018. 
aguas en busca de especies altamente migratorias, demersales y de pequeños pelágicos; un objetivo que, por otra parte, coincide plenamente con lo dispuesto en el examen retrospectivo y prospectivo del Acuerdo del Colaboración en el sector pesquero entre la UE y el Reino de Marruecos de septiembre de 2017, en el que la Comisión Europea sostuvo que la "zona de pesca de Marruecos" incluye las aguas adyacentes al territorio del Sáhara Occidental ${ }^{62}$, esto es, las aguas al sur de $27040^{\prime}$ N. Así:

"Dans ce rapport, la zone de pêche du Maroc doit être comprise comme intégrant les eaux adjacentes au territoire du Sahara occidental. Le Sahara occidental est considéré par l'Union européenne comme étant un territoire non- autonome qui est administré de facto, pour sa plus grande partie, par le Maroc. Le Maroc, quant à lui, soutient le point de vue que le Sahara occidental fait partie intégrante du Royaume et tombe sous sa souveraineté, mais cette souveraineté n'a jamais été reconnue par I'Union et ses Etats membres. L'Union soutient les efforts du Secrétaire Général des Nations Unies pour arriver à une solution politique, juste, durable et acceptable pour les parties, tout en sauvegardant le principe d'autodétermination du peuple du Sahara occidental ainsi que la stabilité de la région. Par conséquent les expressions renvoyant au Maroc, au territoire et à la "zone de pêche marocaine" (termes utilisés dans le Protocole) doivent être comprises comme incluant également le territoire non- autonome du Sahara occidental".

En consecuencia, la negociación del Acuerdo de Pesca y de su Protocolo de aplicación 2018-2022 por parte de la Comisión Europea se ha basado, en nuestra opinión, en varios argumentos cumulativos. Primero, en el último zig-zag jurisprudencial del TJUE que no determina con precisión el alcance espacial del Acuerdo de Colaboración de 2007 y de su Protocolo de aplicación 2014-2018; segundo, en la discutida prohibición legal de celebrar tratados sobre territorios no autónomos ocupados; tercero, en la amplia facultad de apreciación que tienen las instituciones de la UE; y cuarto, en el Dictamen de 2002 del jurisconsulto de la ONU, Hans Corell, según el cual la potencia colonial/ocupante puede disponer de las riquezas naturales del territorio del pueblo colonial siempre que su población apruebe, previo referéndum, la explotación de tales recursos. Es más, en el caso que nos ocupa, la Comisión Europea entiende que la única autoridad con la que se pueden celebrar acuerdos de este tipo es el Reino de Marruecos, desatendiendo claramente la subjetividad internacional del pueblo saharaui y del Frente Polisario, pues "ninguna otra autoridad (entendemos que se refiere al Frente Polisario) podría garantizar el carácter sostenible de la explotación de dichos recursos, ni la gestión y el seguimiento de los fondos de la ayuda sectorial que deben beneficiar al territorio del Sáhara Occidental y sus habitantes ${ }^{63}$. Dicho de otro modo, la

62 Vid. Evaluación retrospectiva y prospectiva del Acuerdo de Colaboración en el sector pesquero entre la UE y el Reino de Marruecos, Informe final, Septiembre 2017, ISBN: 978-92-79-73401-4, p. 5, nota al pie número 7.

${ }^{63}$ Vid. Reglamento del Consejo relativo al reparto de las posibilidades de pesca en virtud 
Comisión "delega" en el Reino de Marruecos la responsabilidad de satisfacer los requisitos de validez del Acuerdo para no posicionarse directamente sobre procedimientos pendientes de solución (ante la CIJ) que corresponden a los asuntos internos de Estados terceros ${ }^{64}$. De esta suerte, la institución comunitaria mantiene un entendimiento mutuo (más bien político) según el cual, mientras la UE consiente la aplicación del tratado en el territorio del Sáhara Occidental, el Reino de Marruecos -a saber, un país que accedió en 2008 al "Estatuto Avanzado" en el marco de la política de vecindad con la UE ${ }^{65}$ - no utiliza este argumento para apoyar sus reivindicaciones de soberanía territorial. They agree to desagree con el fin de preservar y desarrollar una asociación pesquera que sea sostenible con el medio ambiente, económicamente rentable y, según la Comisión, "plenamente conforme con el Derecho Internacional y el Derecho de la UE". De otro modo, habría sido difícil que Marruecos aceptara la celebración de un acuerdo al margen de las aguas adyacentes al territorio del Sáhara Occidental, más si tenemos en cuenta que -en la práctica- sólo las capturas efectuadas en esas aguas representan aproximadamente el $91,5 \%$ del total de la pesca realizada por buques europeos en el marco del Protocolo 2014-2018. Esta realidad ha sido condenada, empero, por varios eurodiputados que han declarado sentirse "(...) alarmados por el modo en que la Comisión gestiona (ha gestionado) el proceso, por la falta de transparencia y por las posibilidades de escrutinio para los miembros del Parlamento Europeo, y por los intentos de la Comisión por eludir el fallo del Tribunal de Justicia de la UE de diciembre de $2016^{166}$. Esta sensibilización del Parlamento Europeo hacia la

del Acuerdo de colaboración de pesca sostenible entre la Unión Europea y el Reino de Marruecos y de su Protocolo de aplicación", COM (2018) 679 final, Bruselas, 8 de octubre de 2018, p. 1; R., CASADO RAIGÓN, "La dimension internationale de la compétence de I'Union Européenne en matière de pêche", en The International Legal Order: Current Needs and Possible Responses, Ed. James Crawford, Abdul Koroma, Said Mahmoudi, Alain Pellet, 2017, pp. 296-300.

${ }^{64}$ Cuando hay procedimientos pendientes ante la CIJ no corresponde a la UE definir su postura sobre controversias entre Estados terceros. Vid. R., GOSALBO BONO, "EI Frente Polisario, las normas del Derecho Internacional y el Derecho de la Unión Europea. Apuntes en torno a la Sentencia del Tribunal General, de 10 de diciembre de 2015, T512/12, Frente Polisario/Consejo", op. cit., p. 60, así como la bibliografía allí citada: EU:T:2015:953, apartados. 215 a 221; EU:T:1995:131, apdo. 38.

${ }^{65}$ El plan de acción UE-Marruecos 2013-2017 para lograr la implementación del Estatuto Avanzado prevé un conjunto de medidas técnicas y comerciales que integren el sector pesquero. Sobre el Estatuto Avanzado de Marruecos, véase, I., MARTÍN, "El Estatuto Avanzado de Marruecos en la UE: ¿cuánto más que la asociación y cuánto menos que la adhesión?", ARI, 158/2008, http://www.realinstitutoelcano.org; http://www.statutavance.com/2185-accord-agricole-le-maroc-et-lue-paraphent-un-documentpourrenforcer-leur-partenariat.html.

${ }^{66}$ Vid. Letter to Members of the European Parliament Committee on International Trade, de 20 de febrero de 2018. El literal en inglés afirma lo siguiente: "We, undersigned Members, feel alarmed about the way that the Commission is managing the process, the lack of transparency and possibilities for scrutiny for members of the European Parliament, and the Commission's attempts to circumvent the ECJ ruling from December 2016". 
causa saharaui no significa, sin embargo, que la institución no haya incurrido en contradicciones ocasionales al respecto ${ }^{67}$.

Por lo que se refiere a las exigencias que a priori debe satisfacer el Reino de Marruecos para consolidar la validez de su Acuerdo con la UE, ya hemos subrayado que el Sáhara Occidental es un territorio no autónomo, en el sentido del artículo 73 de la CNU, cuyo control, ajeno a la UE y a sus Estados miembros, recae sobre el país alauí. Pero, ¿bajo qué condición?. La CIJ nunca ha utilizado la expresión "potencia administradora de facto" para describir la relación entre un Estado y un territorio no autónomo. Por el contrario, en el caso de la anexión de Timor Oriental por la República de Indonesia, un asunto muy similar al del Sáhara, la CIJ calificó de ocupación la intervención militar de la República de Indonesia en Timor Oriental $^{68}$. Si Marruecos controlara el Sáhara como potencia administradora -quod non, como explícita e insistentemente afirman el propio Marruecos y/o el Tribunal General en el apartado 233 del fallo emitido en el caso T-512/12, Frente Polisario/Consejo-, el Estado marroquí tendría la obligación de transmitir al Secretario General de las Naciones Unidas, a título informativo y dentro de los límites que la seguridad y consideraciones de orden constitucional requieran, cualquier información estadística y de naturaleza técnica sobre las condiciones económicas, sociales y educativas -en ningún caso políticas- de dicho territorio ${ }^{69}$. De este modo, también a tenor de las Resoluciones de la Asamblea General de la ONU 1514 (XV) y 2625 (XXV) y/o de los artículos 1.2 y 47 del Pacto Internacional sobre Derechos Económicos, Sociales y Culturales de 1966, Marruecos no podría disponer, como potencia administradora o colonial, de las riquezas naturales del Sáhara Occidental que pertenecen al pueblo saharaui, ni extender su jurisdicción de facto sobre espacios (como, por ejemplo, la zona económica exclusiva), ni tampoco promover cualesquiera inversiones que puedan dificultar la liberación del territorio saharaui. Más aún, Marruecos incurriría en responsabilidad económica por la explotación, agotamiento y daños

\footnotetext{
${ }^{67}$ Vid. E. DÍEZ PERALTA, "El Sáhara Occidental: una piedra en el camino de la asociación privilegiada entre la UE y Marruecos", op. cit., p. 7; J.D. TORREJÓN RODRÍGUEZ, "EI Parlamento Europeo, el Sáhara Occidental y el Acuerdo de Pesca de 2006 entre la Unión Europea y Marruecos", RIPS, vol. 12, 2013, pp. 127-141; del mismo autor La Unión Europea y la cuestión del Sáhara Occidental. La posición del Parlamento Europeo, Editorial Reus, Madrid, 2014, 304 pp.

${ }^{68}$ Vid. Timor Oriental (Portugal c. Australia), sentencia, CIJ Recueil 1995, p. 90, apartado 13. En dicho asunto, la República Portuguesa sostenía que, pese a la ocupación de Timor Oriental por la República de Indonesia, la Commonwealth de Australia sólo podía celebrar un tratado internacional aplicable a Timor Oriental con la República Portuguesa, en su condición de potencia administradora de dicho territorio.

${ }^{69}$ Vid. Artículo 73, letra e) de la CNU, así como la lista adjunta al Informe de 1 de febrero de 2016 del Secretario General de la ONU sobre la "Información sobre los territorios no autónomos transmitida en virtud del artículo 73.e) de la Carta de las Naciones Unidas" $(\mathrm{A} / 71 / 68)$.
} 
causados a dichos recursos y en el consiguiente deber de reparar $^{70}$. Sea como fuere, huelga decir que es la Asamblea General de la ONU quien debe reconocer a un territorio no autónomo y, en consecuencia, identificar su potencia administradora. ¿Y en condición de potencia ocupante?. ¿Puede disponer Marruecos de las riquezas naturales del pueblo colonial bajo esta consideración?. Según el artículo 42 del Reglamento de La Haya de 1907, "se considera como ocupado un territorio cuando se encuentra colocado de hecho bajo la autoridad del ejército enemigo". De este modo, mientras las Resoluciones 34/37 y 35/19 de la Asamblea General de la ONU estiman que el Sáhara Occidental está bajo ocupación marroquí, en el asunto sobre actividades armadas en el Congo, la CIJ puso igualmente de relieve que para saber si "un Estado cuyas fuerzas militares están presentes en el territorio de otro Estado debido a una intervención es una "potencia ocupante" en el sentido en que lo entiende el ius in bello, (es preciso examinar) si existen elementos de prueba suficientes que demuestren que realmente (la) autoridad (del ejército enemigo) estaba establecida y se ejercía en las zonas en cuestión por parte del Estado autor de la intervención" ${ }^{\prime \prime 1}$. Y precisamente esto es lo que sucede con la mayor parte del Sáhara Occidental, que se extiende al oeste del muro de arena edificado y vigilado por el ejército marroquí y que está bajo la autoridad del Reino de Marruecos desde su anexión en dos fases (1976 y 1979). Desde entonces, el territorio ha sido administrado de manera organizada por Marruecos, sin el consentimiento del pueblo del Sáhara Occidental, que no ha ejercido aún su derecho a la libre determinación. Sosteniendo, por lo tanto, que Marruecos ocupa el Sáhara, ¿puede la autoridad alauí explotar sus riquezas naturales, incluidos los recursos pesqueros de las aguas adyacentes?. Si tenemos en cuenta v.g. Ios párrafos 1 y 2 de la Resolución de la Asamblea General de la ONU 1803 $(X V I I)^{72}$ y el mencionado Dictamen de Hans Corell de 2002, es posible entender que si la disponibilidad de los recursos beneficia al pueblo colonial y éste autoriza con carácter previo su explotación, tanto la potencia ocupante como la potencia administradora pueden "gestionar" tales riquezas. El párrafo 2 de la Resolución 50/33, de 6 de diciembre de 1995, y resoluciones posteriores ${ }^{73}$, dispone, a estos efectos, que no hay

\footnotetext{
70 Vid. Carta de Derechos y Deberes Económicos de los Estados, Resolución 3281 (XXIX), 1974; A. REMIRO BROTONS et al. Derecho Internacional, op. cit., pp. 114-115.

${ }^{71}$ Vid. República Democrática del Congo c. Uganda, sentencia, CIJ Recueil 2005, p. 168, apartado 173. Ese mismo principio se aplica a la ocupación de los territorios no autónomos en virtud del artículo 1, apartado 4, del Protocolo Adicional I.

72 Así, "El derecho de los pueblos y de las naciones a la soberanía permanente sobre sus riquezas y recursos naturales debe ejercerse en interés del desarrollo nacional y el bienestar del pueblo del respectivo Estado y que la exploración, el desarrollo y la disposición de tales recursos, así como la importación de capital extranjero para efectuarlos, deberán conformarse a las reglas y condiciones que esos pueblos y naciones libremente consideren necesarios o deseables para autorizar, limitar o prohibir dichas actividades".

73 Por ejemplo, la Resolución 52/72, de 10 de diciembre de 1997; 53/61, de 3 de diciembre de 1998; 54/84, de 6 de diciembre de 1999; 55/138, de 8 de diciembre de 2000; y 56/66, de 10 de diciembre de 2001; D., KINGSBURY, Western Sahara:
} 
que perder de vista "el valor de las inversiones económicas extranjeras llevadas a cabo en colaboración con los pueblos de los territorios no autónomos y conforme con sus deseos con miras a aportar una contribución válida al desarrollo socioeconómico de los territorios". En cualquier caso, si lo que se busca es priorizar y respetar la voluntad y los deseos del pueblo saharaui, lo que se tiene que celebrar es una consulta a través del representante reconocido de dicho pueblo: el Frente Polisario. ¿Y beneficia a los "saharianos originarios del territorio" 0 a las "poblaciones saharianas originarias del territorio"74 el último Acuerdo de Pesca y su Protocolo de aplicación 2018-2022 entre la UE y Marruecos? Si tenemos en cuenta la evaluación ex ante y ex post de los escenarios de renovación del Protocolo $2014-2018^{75}$ que realizó la Comisión Europea en 2017 para identificar, entre otros, los beneficios socieconómicos del tratado para la población local, resulta que la región administrativa de Dakhla-Oued Eddahab (territorio no autónomo del Sáhara Occidental) es la que recibió un mayor apoyo sectorial $^{76}$, seguida de la región LaâyouneSakia-El Hamra, con un 19\%. A la luz de la experiencia negociadora de la Comisión Europea, estos datos proporcionados por Marruecos ${ }^{77}$ son los que, al parecer, permitirían entender que, en efecto, la explotación del territorio y las aguas adyacentes al Sáhara Occidental es beneficiosa para la población colonial. En este sentido, si bien el Acuerdo de Pesca aporta garantías sobre una distribución geográfica equitativa de los beneficios socioeconómicos y, sobre todo, un seguimiento de la asignación de los fondos y de su utilización, es el Reino de Marruecos quien está legitimado para presentar informes periódicos sobre las actuaciones realizadas en virtud del tratado. Y, más allá de que dichos informes puedan presentarse con retraso o vaguedad, aquí nos topamos con otra cuestión controvertida sobre la que ni la Comisión Europea ni el TJUE (ni nosotros mismos, por distanciarnos del objeto del presente trabajo) han querido pronunciarse: ¿quién es, en el Sáhara Occidental, la población colonial titular del derecho de libre determinación? Porque, según el artículo 49, párrafo sexto, del IV Convenio de Ginebra, la potencia ocupante no puede

International Law, Justice and Natural Ressources, Routledge, 2016, 142 pp.

74 Vid. Apartado 7 de la Resolución 3458 a (XXX) de la Asamblea General de la ONU; Estudio The Legal Issues Involved in the Western Sahara Dispute. Use of Natural Resources. Committee on the United Nations. New York City Bar Association, April, 2011.

${ }^{75}$ Vid. Evaluación retrospectiva y prospectiva del Acuerdo de Colaboración en el sector pesquero entre la UE y el Reino de Marruecos, Informe final, Septiembre 2017, op. cit. p. viii.

76 Los proyectos incluidos en el plan de medidas del apoyo sectorial se refieren principalmente a inversiones en infraestructuras y equipos portuarios (un $60 \%$ de la dotación total) y apoyo a la investigación pesquera ( $21 \%$ del total). La dotación total del apoyo sectorial ascendió a 56 millones EUR. Vid. Ibíd., p. iv.

${ }^{77}$ Actualmente, la mayoría de la población que habita en los territorios ocupados son colonos marroquíes. Como hemos comentado en otro lugar, la mayor parte de los saharauis se hallan exiliados, sobre todo en campos de refugiados de la vecina Argelia. Precisamente es desde estos campos donde opera el Frente Polisario. 
efectuar "el traslado de una parte de su propia población civil al territorio por ella ocupado"78.

\subsection{Los intereses recíprocos de la UE y del Reino de Marruecos en la celebración del Acuerdo de Pesca y de su Protocolo de aplicación 2018-2022}

UE-Marruecos, Marruecos-UE, ¿qué intereses recíprocos subyacen a la renegociación de un acuerdo que, al igual que sus predecesores, no está exento de polémica (especialmente legal) ${ }^{79}$ ?. Desde el punto de vista de la Unión Europea, y sin ánimo de profundizar en cuestiones que exceden los márgenes concretos de este trabajo, la negociación del Acuerdo de Pesca y de su Protocolo de aplicación 2018-2022 constituye para la UE una ventaja comparativa para conservar un nivel profundo de cooperación con Marruecos tanto en la gobernanza de los océanos a nivel subregional como en la Cooperación Sur-Sur (CSS $)^{80}$. De hecho, en el último FCM (Foro Crans Montana, marzo 2018) ${ }^{81}$ celebrado en Dajla ("la perla del Atlántico", una ciudad del Sáhara a juicio de los organizadores) Marruecos evidenció su importante papel en la CSS poniendo su sistema de formación a disposición de oficiales y técnicos del África Subsahariana e invirtiendo en la construcción de infraestructuras en algunos países de África Occidental. Ante la inestabilidad en el Magreb y las dificultades europeas, Marruecos quiere aprovechar, en efecto, las nuevas oportunidades de negocio que ofrece África, implicándose en los asuntos de seguridad africanos y enfatizando su papel como estabilizador regional. Para ello, además de destacar su compromiso en la lucha contra el

\footnotetext{
${ }^{78}$ Ese traslado constituye una infracción grave del Protocolo Adicional I (art. 85.4.a), así como un crimen de guerra, a la luz del artículo 8.2.b.viii del Estatuto de Roma de 1998, por el que se crea la Corte Penal Internacional. Vid. Recopilación de los Tratados de las Naciones Unidas, vol. 2187, p. 307. El Reino de Marruecos ha firmado el Estatuto de Roma pero no lo ha ratificado.

79 Sobre las relaciones entre la UE y Marruecos, véase el interesante trabajo de $R$. RIQUELME CORTADO, P. ANDRÉS SÁENZ DE SANTA MARÍA, "El Sáhara Occidental en las relaciones UE-Marruecos", en REMIRO BROTONS, A., (Dir.), MARTÍNEZ CAPDEVILA, C. (Coord.), Unión Europea-Marruecos ¿Una vecindad privilegiada?, Madrid, Academia Europea de Ciencias y Artes, 2012, pp. 533-576.

${ }^{80}$ En la Resolución aprobada por la Asamblea General de las Naciones Unidas 64/222 (21 de diciembre de 2009), documento final de la Conferencia de Alto Nivel de las Naciones Unidas sobre la Cooperación Sur-Sur, dicha cooperación es definida como una empresa común de los pueblos y los países del Sur, surgida de experiencias compartidas y afinidades, sobre la base de unos objetivos y una solidaridad comunes y guiada, entre otras cosas, por los principios del respeto de la soberanía y la implicación nacionales, libres de cualquier condición. La cooperación Sur-Sur no debería considerarse asistencia oficial para el desarrollo. Se trata de una asociación de colaboración entre iguales basada en la solidaridad. Para ampliar esta información véase: http://daccess-ddsny.un.org/doc/UNDOC/GEN/N09/475/18/PDF/N0947518.pdf?OpenElement

${ }^{81}$ El FCM fue creado en Suiza como un encuentro de reflexión internacional parecido al foro de Davos. De ahí que se le conozca como el "Davos de África"; African Development Bank, "Morocco: Country Strategy Paper 2017-2012", 2017, disponible en URL: http://www.afdb.org/
} 
terrorismo mediante la cooperación militar, el país alauí también busca erigirse como referente del Islam moderado y tolerante introduciendo la dimensión religiosa en su política exterior y ¿ganarse, de esta suerte, el favor de los países occidentales y su consiguiente reconocimiento de la soberanía marroquí sobre el Sáhara Occidental?.

Para la UE, el Protocolo con Marruecos complementa una red de acuerdos atuneros en el Atlántico y una red de acuerdos de pesca que cubren la zona de distribución de los stocks de pequeños pelágicos del África Occidental, favoreciendo la implementación de medidas coherentes alineadas con las recomendaciones de las organizaciones regionales de pesca (u organismos regionales de ordenación pesquera, OROP) a nivel subregional de las que Marruecos es, en su mayoría, parte contratante. En concreto, Marruecos participa a través del Instituto Nacional de Investigación Haliéutica (INRH) ${ }^{82}$ en la conservación y explotación del atún rojo y pez espada gestionados por la Comisión Internacional para la Conservación del Atún del Atlántico (ICCAT, según sus siglas en inglés), en el Consejo General de Pesca del Mediterráneo (CGPM), especies pelágicas y demersales), y en la Comisión de Pesca del Atlántico CentroOriental (COPACE, pequeños pelágicos y recursos demersales). En este contexto, debemos destacar igualmente su implicación en el Convenio sobre el Comercio Internacional de Especies Amenazadas de Fauna y Flora Silvestres (CITES) y la deseable y próxima ratificación marroquí del Acuerdo sobre Medidas del Estado Rector del Puerto de la Organización de las Naciones Unidas para la Agricultura, la Pesca y la Alimentación $(\mathrm{FAO})^{83}$. Las pesquerías explotables en las aguas de Marruecos (a saber, seis categorías de pesca distintas, que incluyen especies altamente migratorias, demersales y pequeños pelágicos como la sardina) responden, en definitiva, a las necesidades de las flotas de la UE afectadas $^{84}$ (en particular las flotas española y portuguesa), bien para prolongar sus actividades en aguas adyacentes de la UE (categoría $1^{85}, 2^{86}$ y $5^{87}$ ) bien para facilitar a los armadores de la UE las licencias de pesca que precisen para garantizar su rentabilidad (categoría $4^{88}$ y $6^{89}$ ); todo ello sin olvidar que el Protocolo fomenta la creación de cerca de 500

82 El INRH es una entidad controlada por el Ministerio responsable del sector pesquero para las misiones técnicas que respalda, a su vez, al Departamento de la Pesca Marítima (DPM), una entidad administrativa de dicho Ministerio; J.M., SOBRINO HEREDIA, "Los acuerdos internacionales de pesca, instrumentos indispensables de la Política Pesquera Común de la Unión Europea, Noticias de la Unión Europea, no 326, 2012, pp. 51-65.

83 Vid. Acuerdo sobre medidas del Estado rector del puerto destinadas a prevenir, desalentar y eliminar la pesca ilegal, no declarada y no reglamentada. Antecedentes y guía de aplicación, FAO, Circular de Pesca y Acuicultura no 1074, FIPI/C 1074 (Es), ISSN 2070-7061.

${ }^{84}$ Se trata de los buques de once Estados miembros de la UE

${ }^{85}$ Buques cerqueros artesanales dedicados a los pequeños pelágicos.

${ }^{86}$ Buques palangreros artesanales interesados en las especies demersales

${ }^{87}$ Buques atuneros cerqueros

${ }^{88}$ Buques arrastreros y palangreros industriales centrados en las especies demersales

${ }^{89}$ Buques arrastreros industriales de especies pelágicas 
puestos de trabajo ocupados por marineros de la UE y, especialmente, por marineros procedentes de la región ultraperiférica (RUP) de las Islas Canarias. El Protocolo 2018-2022 prevé posibilidades de pesca para 128 buques en seis categorías: dos categorías de pesca artesanal en el norte (pelágica con redes de cerco -categoría 1, 22 buques- y palangre de fondo -categoría 2, 35 buques-); pesca artesanal en el sur con línea y caña (categoría 3, 10 buques); pesca demersal con artes de arrastre de fondo y palangre de fondo (categoría 4, 16 buques); pesca artesanal del atún con caña (categoría 5, 27 buques); y pesca pelágica industrial con redes de arrastre pelágico o semipelágico y redes de cerco con jareta (categoría 6, 18 buques). En esta categoría, las capturas de los buques de la UE se limitan a una cantidad diferente según el año de aplicación del Protocolo.

Posibilidades de pesca a la luz del Protocolo 2018-2022

\begin{tabular}{|c|c|c|c|c|c|}
\hline \multicolumn{4}{|c|}{ Pesca artesanal } & $\begin{array}{c}\text { Pesca } \\
\text { demersal }\end{array}$ & $\begin{array}{c}\text { Pesca } \\
\text { pelágica } \\
\text { industrial }\end{array}$ \\
\hline $\begin{array}{l}\text { Pesca } \\
\text { pelágica } \\
\text { en el } \\
\text { norte: } \\
\text { redes de } \\
\text { cerco }\end{array}$ & \begin{tabular}{|c|} 
Pesca \\
artesanal \\
en el sur: \\
líneas y \\
cañas
\end{tabular} & $\begin{array}{c}\text { Pesca } \\
\text { artesanal en } \\
\text { el norte: } \\
\text { palangres de } \\
\text { fondo }\end{array}$ & $\begin{array}{c}\text { Pesca } \\
\text { artesanal } \\
\text { del atún: } \\
\text { cañas }\end{array}$ & $\begin{array}{l}\text { Palangres } \\
\text { de fondo y } \\
\text { redes de } \\
\text { arrastre de } \\
\text { fondo }\end{array}$ & $\begin{array}{l}1 \\
85000 t \text { año: } \\
\text { España: } \\
496,2 \mathrm{t} \\
2 \\
90000 \mathrm{t} \text { año: } \\
\text { España: } \\
525,4 \mathrm{t} \\
3 \text { y } 4 \text { años: } \\
100000 \mathrm{t} \\
\text { España: } \\
583,8 \mathrm{t}\end{array}$ \\
\hline $\begin{array}{c}22 \\
\text { España }\end{array}$ & 10 España & $\begin{array}{l}25 \text { España } \\
10 \text { Portugal }\end{array}$ & $\begin{array}{l}27 \text { España } \\
4 \text { Francia }\end{array}$ & $\begin{array}{l}11 \text { España } \\
4 \text { Portugal }\end{array}$ & \\
\hline $\begin{array}{c}22 \\
\text { buques }\end{array}$ & $\begin{array}{c}10 \\
\text { buques }\end{array}$ & 35 buques & 27 buques & 16 buques & \\
\hline
\end{tabular}

Fuente: Elaboración propia a partir del Reglamento del Consejo relativo al reparto de las posibilidades de pesca en virtud del Acuerdo de Colaboración de Pesca Sostenible entre la Unión Europea y el Reino de Marruecos y de su Protocolo de aplicación, COM (2018) 679 final, Bruselas, 8 de octubre de 2018, pp. 7 y 8.

Por lo que se refiere a Marruecos, más allá de su "Estatuto Avanzado" en la UE y del programa "Réussir le Statut Avancé"90 que le acompaña, el

90 La Política Europea de Vecindad, que sucedió en el tiempo a la Asociación Euromediterránea nacida en la Conferencia de Barcelona de 1995 y que se superpuso a la misma no siempre de manera consistente y armoniosa, siempre ha buscado pasar de una integración basada en los flujos físicos a otra impulsada por la convergencia normativa. Teniendo presente que la integración depende en gran medida de su componente institucional, las capacidades marroquíes deben mejorar para hacer frente (aprender y aprehender) el acervo comunitario. Para ello, en el $11^{\circ}$ Consejo de 
Gobierno alauí lanzó en 2009 la Estrategia Halieutis 2020 dirigida a desarrollar el sector pesquero de Marruecos y a triplicar, con él, la contribución de la pesca al PIB en condiciones que garanticen la explotación sostenible. Actualmente, la pesca representa el $2 \%$ del PIB marroquí y sus exportaciones de pescado aumentan hasta un $9 \%$ de las ventas totales del país. En palabras del Ministro marroquí de Agricultura y Pesca Marítima, Aziz Ajanuch, la Estrategia Halieutis es "(...) un plan de reestructuración y de inversión de la pesca tradicional, de altura y de bajura, y de la industria pesquera". Ahora bien, para que la implementación de Halieutis pueda acelerarse, el apoyo sectorial que le brinda el Protocolo es absolutamente esencial. Sin él, Marruecos tendría que ejecutar sus proyectos en función de la disponibilidad del presupuesto estatal. Así, por ejemplo, el Protocolo da acceso al excedente (esto es, a recursos que no son completamente explotados por las flotas nacionales ${ }^{91}$ ) reduciendo las interacciones entre buques de pesca y favoreciendo, al mismo tiempo, las interacciones económicas (marineros nacionales, desembarcos en Marruecos). Por tanto, para Marruecos es importante establecer alianzas de colaboración que favorezcan la puesta en marcha de sus políticas sectoriales para la pesca y también para la Estrategia de Crecimiento Azul que complementa la Estrategia Halieutis. Como es sabido, la iniciativa "Cinturón Azul" es un proyecto que pretende aprovechar las limitaciones ambientales para transformarlas en oportunidades económicas en el marco del objetivo de desarrollo sostenible (ODS) 14 de las Naciones Unidas ${ }^{92}$. A mayor abundamiento, los intereses comerciales de Marruecos en la región no sólo se centran en la pesca sino en la exploración (¿y posterior explotación?) de petróleo y gas en las aguas del Sáhara Occidental, concretamente en la cuenca de El Aaiún ${ }^{93}$

\footnotetext{
Asociación UE-Marruecos organizado el 17 de diciembre de 2013 en Bruselas, la UE aprobó un paquete de medidas específicas bajo el programa "Réussir le Statut Avancé". El programa tiene carácter multisectorial, abarcando una aproximación legislativa al acervo comunitario y una cooperación reforzada en políticas sectoriales como inter alia la empresa, la energía o el transporte. Vid. Royaume du Maroc, Programme Réussir le Statut Avancé Phase II. Financé par I'Union UE, abril 2017, http://www.bmeia.gv.at; I. MARTÍN, "El Estatuto Avanzado de Marruecos en la UE: ¿cuánto más que la asociación y cuánto menos que la adhesión?", ARI, 158/2008, http://www.realinstitutoelcano.org; http://www.statut3avance.com/2185-accord-agricole-le-maroc-et-lue-paraphent-

undocumentpour-renforcer-leur-partenariat.html; C. MARTÍNEZ CAPDEVILA, "El "Estatuto Avanzado" de Marruecos", Revista de Derecho Comunitario Europeo, núm. 34, 2009, pp. 895-914.

91 La flota pesquera marroquí cuenta con unas 20.000 unidades con una producción valorada en 1,3 millones de toneladas y con un valor próximo al millar de euros. El $85 \%$ de la flota está formada por unidades artesanales, el 13\% representa unidades de pesca costera y el $2 \%$ de la flota está compuesta por unos 500 arrastreros de altura.

92 Vid. "Crónica ONU. Objetivo 14 - Conservar y utilizar sosteniblemente los océanos, los mares y los recursos marinos para del desarrollo sostenible", http:www.unchronicle.un.org

${ }_{93}$ Vi.d U.S Geological Survey, 2008 Minerals Yearbook: Morocco and Western Sahara (Advance Release), February 2010, http://minerals.usgs.gov/minerals/pubs/country/2008/myb3-2008-mo-wi.pdf, p. 8; A.,
} 
La UE y Marruecos están interesados, en consecuencia, en el Acuerdo de Pesca y su Protocolo de aplicación 2018-2022 (y siguientes) ${ }^{94}$ aunque sin obviar, naturalmente, las mejoras que a la luz de la experiencia convencional anterior sean necesarias para satisfacer sus recíprocas expectativas. Veamos cuáles eran - y si se han corregido- las principales deficiencias detectadas en el Protocolo 2014-2018.

Con respecto al objetivo de la explotación sostenible, el nuevo Protocolo 2018-2022 tendría que haber intensificado la cooperación científica entre ambas partes para lograr un mayor intercambio de información y de diagnóstico sobre el estado de los recursos (tanto de las especies objetivo -especialmente de los stocks demersales, dada la falta de información científica sobre los mismos y su naturaleza multi-especies- como de las capturas no deseadas y de los stocks poco conocidos). Para ello, quizá hubiera podido adoptar un enfoque precautorio e insistir en los programas de observación científica a bordo. En cuanto a la cláusula técnica del Protocolo 2014-2018 sobre las obligaciones de embarque de marineros marroquíes por los armadores de la $U E$, el nuevo tratado incrementa el número de contrataciones de dichos trabajadores por lo que no creemos que haya tenido muy en cuenta algunos problemas identificados y relacionados con el cumplimiento de las normas de la Organización Marítima Internacional (OMI), en particular con el Convenio para la Formación, Titulación y Guardia para la Gente de Mar (STCW, 1978). Siempre en el marco de las cláusulas técnicas, el nuevo Protocolo 20182022 mantiene la disposición relativa a los desembarques obligatorios en Marruecos, sin prestar especial atención a las categorías de pesca artesanal, pero sí incrementando la penalización del incumplimiento de dicha obligación hasta un $15 \%$ (en lugar del 5\% del Protocolo anterior 2014-2018). No tratándose de una venta obligatoria de productos de la UE a las industrias marroquíes, la cláusula ya fue objeto de clarificación durante sucesivas Comisiones Mixtas para distinguir entre ventas locales y desembarques en territorio marroquí, incluido el transporte inmediato a la UE por carretera. Así, pese a que los armadores de la UE sostienen que desembarcar en Marruecos resulta demasiado costoso, las últimas recomendaciones parecen abogar por mantener las aclaraciones aprobadas en la tercera Comisión Mixta, es decir, descargar capturas en puertos sin que sea necesaria la venta local. Finalmente, el nuevo Protocolo 2018-2022 tampoco mejora sensiblemente los mecanismos vigentes para gestionar el consumo de cuotas ni revisa los cánones de acceso para reequilibrar la importancia relativa de los costes de acceso

BOUKHARI, "Las dimensiones internacionales del conflicto del Sahara Occidental y sus repercusiones para una alternativa marroquí", Documento de Trabajo (DT) no 16/2004, de 19 de abril de 2004, www.realinstitutoelcano.org

94 Sobre las relaciones pesqueras entre la UE y Marruecos, véase el trabajo de J. GONZÁLEZ GIMÉNEZ, "Las relaciones pesqueras entre la UE y Marruecos: mismos problemas... ¿distintas soluciones?" en LINÁN NOGUERAS, D.J. Las crisis políticas y económicas: nuevos escenarios internacionales, Madrid, Tecnos, 2014, pp. 306-318. 
soportados por las distintas categorías, procurando la convergencia con el sistema de fijación de precios de las capturas ${ }^{95}$.

\section{OBSERVACIONES FINALES}

Es indudable que las cuestiones prejudiciales planteadas por la jurisdicción inglesa ante el TJUE constituyen temas de gran calado político y mediático y de una envergadura incuestionable en el ámbito de las relaciones entre los ordenamientos jurídicos comunitario e internacional, toda vez que dichos interrogantes contaminan el Derecho de la UE de cuestiones polémicas -como la controvertida descolonización del Sáhara Occidentalconsiderada hasta la fecha por el Derecho internacional.

En este orden de ideas, la sentencia del TJUE, de 27 de febrero de 2018, en el caso C-266/16, excluye el territorio del Sáhara Occidental del "territorio de Marruecos" consiguiendo que el Tribunal "se desentienda" de las dos primeras cuestiones prejudiciales planteadas por el Tribunal Superior de Justicia (Inglaterra y País de Gales), Sala de lo ContenciosoAdministrativo, Reino Unido, (High Court of Justice (England \& Wales), Queen's Bench División (Administrative Court). Empero, el Tribunal no ha podido disfrazar su desigual valoración ante situaciones objetivamente similares pues, si bien en el asunto Brita excluyó los productos originarios de Cisjordania del ámbito de aplicación territorial del Acuerdo de Asociación entre la entonces Comunidad Europea e Israel, en 2018 el TJUE parece abogar por que los productos originarios de las aguas adyacentes al Sáhara Occidental pueden ser explotados por las partes interesadas (UE-Marruecos), ya que su relación convencional es un acto iure imperii que nada tiene que ver con un acuerdo de asociación relativo a los productos originarios saharauis. Es decir, para que los productos originarios del Sáhara Occidental (incluidos los procedentes de sus aguas adyacentes) puedan ser aprovechados por el pueblo colonial, ¿debe la UE celebrar un Acuerdo de Asociación con el Frente Polisario? Pues obviamente esto podría interpretarse como un reconocimiento o asistencia de la UE al Sáhara, menoscabando su realpolitik con Marruecos y/o facilitando que el país alauí amenace con acudir a las instancias de la Organización Mundial del Comercio (OMC) de la que es Estado miembro desde el 1 de enero de 1995. Por otro lado, si el Tribunal hubiera prohibido la importación de productos originarios del Sáhara Occidental, es obvio que la prohibición afectaría tanto a la jurisdicción inglesa como a los Tribunales de todos los Estados miembros de la UE, desencadenando importantes consecuencias comerciales.

Y si el TJUE no ha querido "polemizar legalmente" sobre el Sáhara, tampoco lo ha hecho la Comisión Europea al celebrar el Acuerdo de Pesca

\footnotetext{
${ }^{95}$ Vid. Evaluación retrospectiva y prospectiva del Acuerdo de Colaboración en el sector pesquero entre la UE y el Reino de Marruecos, Informe final, Septiembre 2017, op. cit., pp. i-vi.
} 
y su Protocolo de aplicación 2018-2022. De esta suerte, amparándose en el "zig-zag jurídico-semántico" del Tribunal y en su propia facultad de apreciación (que parece haber "escapado" del control judicial del TJUE), la Comisión Europea mira hacia otro lado para no entrometerse en cuestiones que deben ser resueltas por el Derecho internacional justificando, en todo caso, su posible inquietud legal a la luz del Dictamen de 2002 del jurisconsulto de las Naciones Unidas, Hans Corell, según el cual, tanto la potencia colonial como la potencia ocupante de un territorio colonial pueden disponer de los recursos de su pueblo si dicho pueblo lo acepta previamente y se ve beneficiado. En otras palabras, el TJUE y la Comisión parecen entender que si Marruecos, en su condición de potencia ocupante, satisface los requisitos mencionados, su relación convencional es "plenamente conforme con el Derecho internacional y el Derecho de la UE". Ahora bien, si Marruecos es, según la UE, el único que puede celebrar tratados de este tipo y garantizar la explotación de esos recursos de conformidad con el Derecho internacional, esto es, respetando la primacía de los intereses de los habitantes consagrada en el artículo 73 de la Carta de las Naciones Unidas y el mencionado principio de soberanía permanente, ¿no desatiende la UE, por un lado, la subjetividad internacional del pueblo saharaui y del Frente Polisario para, por otro, apoyar la condición de Marruecos como potencia administradora ${ }^{96}$ del Sáhara, y no como potencia ocupante, que es precisamente "como se califica" el reino alauí para evitar inter alia los impedimentos legales que, sobre los recursos del pueblo colonial, pesan sobre la potencia colonial. Más aún, Marruecos no puede aplicar un tratado del que es parte en un territorio del que no es soberano. Los objetivos políticos de la UE y sus políticas económicas no pueden permutar al Frente Polisario por el Reino de Marruecos como entidad organizadora y/o supervisora de una consulta que es ajena al concepto jurídico internacional de autodeterminación, al tiempo que tampoco pueden sustituir el consentimiento de "los saharianos originarios del territorio" por el beneplácito de los outsiders ${ }^{97}$.

Algunos detalles del nuevo acuerdo de pesca revelan, por otro lado, que el último Protocolo 2018-2022 es más significativo para Marruecos que para la UE. De esta suerte, aunque la pesca de pequeños pelágicos ha aumentado en 15.000 toneladas (de 85.000 TN se ha pasado a 100.000 TN), la flota de la UE sólo ha conseguido dos unidades más con respecto

\footnotetext{
${ }^{96}$ Como es sabido, la condición de potencia administradora es atribuida por la Asamblea General de la ONU a un Estado para que promueva la descolonización de un territorio colonial. Esta condición fue atribuida oficialmente a España, nunca a Marruecos. Así lo han reconocido también recientemente varios Tribunales españoles como, por ejemplo, la Audiencia Nacional. Vid. J. SOROETA LICERAS, "La sentencia de 10 de diciembre de 2015 del Tribunal General de la UE (T-512/12), primer reconocimiento en vía judicial europea del estatuto del Sáhara Occidental y de la subjetividad internacional del Frente Polisario", op. cit., p. 20.

97 Por outsiders nos referimos a los marroquíes instalados en el Sáhara, los cuales -a juicio de Marruecos- tendrían derecho de voto en un hipotético referéndum, al formar parte (siempre desde la perspectiva marroquí) del pueblo saharaui.
} 
al acuerdo anterior (128 buques frente a los 126 del Protocolo 20142018), siendo la contrapartida financiera el aspecto que más ha mejorado para Marruecos pues, frente a los 30 millones de euros anuales (MEUROS) percibidos entre 2014-2018, el reino alauí recibirá 52 MEUROS durante el período 2018-2022, es decir, 22 MEUROS más que con el Protocolo anterior. De esta suma, 40 MEUROS anuales serán abonados por la Comisión Europea, debiendo pagar los armadores los otros 12 MEUROS en concepto de licencias de pesca. En definitiva, teniendo presentes todas estas consideraciones, quizá no sea ocioso preguntarse si el nuevo acuerdo es realmente un acuerdo gagnant-gagnant como sostiene la jefa de la delegación de la UE en Marruecos, Claudia Wiedey, o si no es Marruecos quién, en esta ocasión, ha arrimado más y mejor el ascua a su sardina.

\section{Bibliografía}

African Development Bank, "Morocco: Country Strategy Paper 20172021", 2017, disponible en https://www.afdb.org/

ALGUERÓ CUERVO, J.I., El Conflicto del Sahara Occidental, desde una perspectiva canaria, Colección La Diáspora, Gobierno de Canarias, 2003, 550 pp.

ALONSO GARCÍA, R., "La cuestión prejudicial, piedra angular de la integración europea", European Inklings, no 4, 2014, pp. 9-28.

ANNONI, A., "C'è un giudice per il Sahara occidentale?", Rivista di Diritto Internazionale, Vol. 99, no 3, 2016, pp. 866-876;

AZAROV, V., "The Commission's Proposals to Correct EU-Morocco Relations and the EU's Obligation Not to Recognise as Lawful the 'Illegal Situation' in Western Sahara", en <https://www.ejiltalk.org/tag/morocco>

BÁRBULO, T., La historia prohibida del Sáhara Español. Las claves del conflicto que condiciona las relaciones entre España y el Magreb, Ed. Península, 2017, 363 pp.

BARREÑADA, R., I., y OJEDA, Sáhara Occidental. 40 años después, Madrid, Los Libros de la Catarata, 2016, 320 pp.

BELANI, A., "L'UE et son doublé standard sur le statut des territoires occupés", http://www.algeriepatriotique.com/article/contribution

BOTHE, M., "The Administration of Occupied Territory", en A. Clapham, P. Gaeta y M. Sassòli (eds.), The 1949 Geneva Conventions: A Commentary, Oxford University Press, Oxford, 2015, 1760 pp.

BOUKHARI, A., "Las dimensiones internacionales del conflicto del Sahara Occidental y sus repercusiones para una alternativa marroquí", Documento de Trabajo (DT) no 16/2004, de 19 de abril de 2004, www.realinstitutoelcano.org

CASADO RAIGÓN, R., "La dimension internationale de la compétence de I'Union Européenne en matière de pêche", en The International Legal Order: Current Needs and Possible Responses, Ed. James Crawford, Abdul Koroma, Said Mahmoudi, Alain Pellet, 2017, pp. 287-311. DOI: https://doi.org/10.1163/97890043314375021 
CANNIZZARO, E., "In defence of Front Polisario: The ECJ as a global jus cogens maker", CMLRev, vol. 55, 2018, pp. 569-588.

DAVID, É., Principes de droit des conflicts armés, $5^{a}$ ed. Bruylant, Bruselas, 2012, 1151 pp. DOI: https://doi.org/10.7202/1017547ar

DÍEZ PERALTA, E., "El Sáhara Occidental: una piedra en el camino de la asociación privilegiada entre la UE y Marruecos", La Ley Unión Europea, no 46, marzo 2017, Ed. Wolters Kluwer, 32 pp.

DÍEZ PERALTA, E., "Made in Israel": Reflexiones en torno al etiquetado de mercancías fabricadas en los territorios palestinos ocupados. A propósito de la Sentencia Brita del Tribunal de Justicia de la Unión Europea, de 25 de febrero de 2010 (C-386/08)", Revista General de Derecho Europeo, no 21, 2010, 35 pp.

DINSTEIN, Y., The International Law of Belligerent Occupation, Cambridge University Press, Cambridge, 2009. DOI: https://doi.org/10.1017/CB09780511818257

DUBUISSON, F., POISSONNIER, G., "La question du Sahara occidental devant le Tribunal de I'Union européen, une application approximative du droit international relatif aux territoires non autonomes", Journal du Droit International, no. 2, 2016,

DUBUISSON, F., POISSONNIER, G., "La Cour de justice de I'Union européenne et la question du Sahara occidental: cachez cette pratique (illégale) que je ne saurais voir", RBDI, 2016/2, p. 599-634

Estudio The Legal Issues Involved in the Western Sahara Dispute. Use of Natural Resources. Committee on the United Nations. New York City Bar Association, April, 2011.

FERER LLORET, J., "El conflicto del Sahara Occidental ante los tribunales de la Unión Europea", RGDE, vol. 42, 2017, pp. 15-64.

FERNÁNDEZ MOLINA, I., Moroccan Foreign Policy under Mohammed VI, Durham Modern Middle East and Islamic World East Series, London and New York, Routledge, 2016, Xvi +, 260 pp.

GÂLEA, I, "The Law of Treaties in the Recent Case-Law of the European Court of Justice: the Frente Polisario Case, Interpretation and Territorial Application of Treaties", Bucharest University Annual Revue, 2017, disponible en <http://drept.unibuc.ro/Ion-GALEA-Lawof-Treaties-in-the-Recent-Case-Law-of-European-Court-of-Justicethe-Frente-Polisario-Case-Interpretation-and-Territorial-Applicationof-Treaties-s746-a999-en.htm>

GÓMEZ JUSTO, J.C., "El Frente Polisario: la historia de un Movimiento de Liberación Nacional", Revista Internacional de Pensamiento Político, 2013, vol. 8, pp. 261-280.

GONZÁLEZ GIMÉNEZ, J., "Las relaciones pesqueras entre la UE y Marruecos: mismos problemas....¿distintas soluciones?", en LIÑÁN NOGUERAS, D.J. Las crisis políticas y económicas: nuevos escenarios internacionales, Madrid, Tecnos, 2014, pp. 306-318.

GONZÁLEZ VEGA, "El Sáhara Occidental, de nuevo, en Luxemburgo", La Ley Unión Europea, no 56, 2018.

GONZÁLEZ VEGA, "A Bridge over Troubled Waters (and Sands). A critical Sight on Spain's Role in Western Sahara", Spanish Yearbook of 
International Law, 20, 2016, pp. 255-277.

GONZÁLEZ VEGA, J.A., "La Guerra de los Mundos: realidad versus formalismo jurídico o el poder de la interpretación (a propósito de la sentencia TJUE de 27 de febrero de 2018, Western Sahara Campaign UK, C-266/16), RDCE, 60, mayo-agosto (2018), pp. 550.

GOSALBO BONO, R., "El Frente Polisario, las normas del Derecho Internacional y el Derecho de la Unión Europea. Apuntes en torno a la Sentencia del Tribunal General, de 10 de diciembre de 2015, T512/12, Frente Polisario/Consejo", Revista de Derecho Comunitario Europeo, núm. 53, enero/abril (2016), pp. 22-77.

HERNANDO DE LARRAMENDI, M., y TOME ALONSO B., "The Return of Morocco to the UA: End of the Policy of the Empty Chair", en IEMed Mediterranean Yearbook, 2017, pp. 229-232, disponible en: http://www. Iemed.org/observatory/arees-danalisi/arxiusadjunts/ anuari/med.2017/IEMed_MedYearbook2017_morocco_african_union_ Larramendi_alonso/pdf

HIPOLD, Peters, "Self-determination at the European Courts: The Front Polisario Case or The Unintended Awakening of a Giant", European Papers, Vol. 2, 2017, No 3, pp. 907-921.

HUMMELBRUNNER, S. y CARLIJN PRICKARTZ, A., (2016): "It's not the Fish that Stinks! EU Trade Relations with Morocco under the Scrutiny of the General Court of the European Union", Utrecht Journal of International and European Law, 32(83), pp. 19-40.

JIMÉNEZ SÁNCHEZ, C., El conflicto del Sáhara Occidental: el papel del Frente Polisario, Capítulo X, II, A, Fundación Universitaria Andaluza, 2015, $230 \mathrm{pp}$.

KASSOTI, E., "The Council v. Front Polisario Case: The Court of Justice's Selective Reliance on International Rules on Treaty Interpretation (Second Part)", European Papers, vol. 2, 2017, no 1, p. 40.

KINGSBURY, D., Western Sahara: International Law, Justice and Natural Ressources, Routledge, 2016, 142 pp.

LÓPEZ MARTÍN, A.G., "Aplicación de tratados sucesivos concernientes a la misma materia. Análisis del artículo 30 del Convenio de Viena de 1969 sobre Derecho de los Tratados", Anuario Colombiano de Derecho Internacional, vol. 10, 2017, pp. 51-84.

LÓPEZ MARTÍN, A.G. y J.A. PEREA UNCETA, Creación de Estados, secesión y reconocimiento, Ed. Tirant LoBlanch, Valencia, 2018, 322 pp.

MARTÍN, I., "El Estatuto Avanzado de Marruecos en la UE: ¿cuánto más que la asociación y cuánto menos que la adhesión?", ARI, 158/2008, http://www.realinstitutoelcano.org; http://www.statut3avance.com/2185-accord-agricole-le-maroc-etlue-paraphent-undocumentpour-renforcer-leur-partenariat.html.

MARTÍNEZ CAPDEVILA, C., "El "Estatuto Avanzado" de Marruecos", Revista de Derecho Comunitario Europeo, núm. 34, 2009, pp. 895914.

MILANO, E., "Front Polisario and the Exploitation of Natural Resources by the Administrative Power", European Papers, Vol. 2, 2017, No 3, pp. 953-966. 
OANTA, G.A., "Tres sentencias claves para la delimitación del contorno jurídico de las competencias convencionales de la Unión Europea en el ámbito pesquero", en Revista de Derecho Comunitario Europeo, no 53, 2016, pp. 201-231. DOI: http://dx.doi.org/10.18042/cepc/rdce.53.05

ODERMATT, J., "Council of the European Union v. Front Populaire pour la Libération de la Saguia-El-Hamra et Du Rio de Oro (Front Polisario)", AJIL, Vol.111, No 3, 2017, pp. 731-738.

OPPENHEIN, L., "The Legal Relations between and Occupying Power and the Inhabitants", Law Quarterly Review, 1917, vol. 33.

PEIFFERT, O., "Le recours $d$ ' un mouvement de libération nationale à l'encontre d'un acte d'approbation d'un accord international de I'Union: aspects contentieux", Revue Trimestrielle de Droit Européen, Dalloz, 2016, pp. 319-336.

RASI, A., "Front Polisario: A Step Forward in Judicial Review of International Agreements by the Court of Justice?, European Papers, Vol. 2, 2017, No 3, pp. 967-975.

REMIRO BROTONS, A., R.M. RIQUELME CORTADO, E. ORIHUELA CALATAYUD, J. DÍEZ-HOCHLEITNER, L.PÉREZ-PRAT DURBÁN, Derecho Internacional, Ed. McGrawHill, 1997, 1269 pp.

ROLDÁN BARBERO, J., "La aplicación territorial del Derecho de la Unión Europea y el Derecho Internacional", Revista de Derecho Comunitario Europeo, núm. 51, 2015, pp. 453-490.

RIQUELME CORTADO, R., ANDRÉS SÁENZ DE SANTA MARÍA, P., "EI Sáhara Occidental en las Relaciones UE-Marruecos", en REMIRO BROTONS, A., (Dir.), MARTÍNEZ CAPDEVILA, C. (Coord.), Unión Europea-Marruecos ¿Una vecindad privilegiada?, Madrid, Academia Europea de Ciencias y Artes, 2012, pp. 533-576.

RUIZ MIGUEL, C., "El largo camino jurídico y político hacia el Plan Baker II. ¿Estación de término?", DT/WP, Real Instituto Elcano, 13 de octubre de 2003.

SIMON, D., RIGAUX, A., "Le Tribunal et le Droit international des traités: un arrêt déconcertant (Tribunal de I'Union Européenne, 10 décembre 2015, affaire T-512/12, Front Polisario c/ Conseil soutenu par la Commission", LexisNexis, Europe, núm. 2, Février 2016.

SOBRINO HEREDIA, J.M., "Los acuerdos internacionales de pesca, instrumentos indispensables de la Política Pesquera Común de la Unión Europea, Noticias de la Unión Europea, no 326, 2012, pp. 5165.

SOROETA LICERAS, J., El conflicto del Sáhara Occidental, reflejo de las contradicciones y carencias del Derecho Internacional, Universidad del País Vasco, Servicio Editorial 2001, 370 pp.

SOROETA LICERAS, J., "La sentencia de 10 de diciembre de 2015 del Tribunal General de la UE (T-512/12), primer reconocimiento en vía judicial europea del estatuto del Sahara Occidental y de la subjetividad internacional del Frente Polisario" (RI §417010), Revista General de Derecho Europeo, no 38, 2016. 
SOROETA LICERAS, J., "La cuestión de la legalidad de la explotación de los recursos naturales del Sahara Occidental ante el Tribunal de Justicia de la Unión Europea", en la obra colectiva Retos para la Acción Exterior de la Unión Europea (C.MARTÍNEZ CAPDEVILA y MARTÍNEZ PÉREZ, E.J. (Directores), AEPDIRI, Tirant Lo Blanch, Valencia, 2017, pp. 73-96.

SOROETA LICERAS, J., "La jurisprudencia del TJUE en relación con la legalidad de la explotación de los recursos naturales del Sahara Occidental o el dogma de la inmaculada legalidad de la acción exterior de la Unión Europea y sus consecuencias", RGDE, núm. 46, octubre 2018, p. 113.

TEIJO GARCÍA, C., "Una aproximación a la práctica convencional de los acuerdos de asociación pesquera suscritos por la Comunidad Europea", en PUEYO LOSA, J. JORGE URBINA, J., (Coordinadores), La cooperación internacional en la ordenación de los mares y océanos, Ed. Iustel, Madrid, 2009, pp. 263-291.

TORREJÓN RODRÍGUEZ, J.D., "El Parlamento Europeo, el Sáhara Occidental y el Acuerdo de Pesca de 2006 entre la Unión Europea y Marruecos", RIPS, ISSN 1577-239X, vol. 12, no 2, 2013, pp. 127141.

TORREJÓN RODRÍGUEZ, J.D., La Unión Europea y la cuestión del Sáhara Occidental. La posición del Parlamento Europeo, Editorial Reus, Madrid, 2014, 304 pp.

ZOUBIR, Y.H., "Tipping the Balance Towards Intra-Maghreb Unity in Light of the Arab Spring", The International Spectator, 47 (3), 2012, pp. 83-99.

También puede ser útil consultar los recursos del Instituto sobre el Sahara Occidental de la Universidad de Santiago de Compostela (USC) que dirige el Prof. Dr. C. Ruiz Miguel y el enlace < http://www.oxfordbibliographies.com/view/document/obo-

9780199796953/obo-9780199796953-0095.xml> 